\title{
Revealing Carbon Capture Chemistry with 17-Oxygen NMR Spectroscopy
}

Astrid H. Berge, ${ }^{1}$ Suzi M. Pugh, ${ }^{1}$ Marion I. M. Short, ${ }^{1}$ Ziheng Lu, ${ }^{2}$ Jung-Hoon Lee, ${ }^{3}$ Chris J. Pickard, ${ }^{2,4}$

Alexander C. Forse ${ }^{1 *}$

${ }^{1}$ Department of Chemistry, University of Cambridge, Lensfield Road, Cambridge, CB2 1EW, U.K.

${ }^{2}$ Department of Materials Science and Metallurgy, University of Cambridge, 27 Charles Babbage Road, Cambridge, CB3 0FS, U.K

${ }^{3}$ Computational Science Research Center, Korea Institute of Science and Technology (KIST), Seoul 02792, Republic of Korea

${ }^{4}$ Advanced Institute for Materials Research, Tohoku University, Aoba, Sendai, 980-8577, Japan.

\begin{abstract}
Carbon dioxide capture is an essential greenhouse mitigation technology to achieve netzero emissions. A key hurdle to the design of improved carbon capture materials is the lack of adequate tools to characterise how $\mathrm{CO}_{2}$ adsorbs. Solid-state nuclear magnetic resonance (NMR) spectroscopy is emerging as a promising probe of $\mathrm{CO}_{2}$ capture, but it remains challenging to distinguish different adsorption products. Here we perform a comprehensive computational investigation of 22 amine-functionalised metal-organic frameworks and discover that ${ }^{17} \mathrm{O} \mathrm{NMR}$ is a powerful probe of $\mathrm{CO}_{2}$ capture chemistry that provides excellent differentiation of ammonium carbamate and carbamic acid species. The computational findings are supported by ${ }^{17} \mathrm{O}$ NMR experiments on a series of $\mathrm{CO}_{2}$-loaded frameworks that clearly identify ammonium carbamate chain formation and provide new evidence for a mixed carbamic acid - ammonium carbamate adsorption mode. The fine sensitivity of ${ }^{17} \mathrm{O}$ NMR to local chemistry also shows that hydrogen bonding schemes proposed in previous ammonium carbamate chain structures may be inaccurate and new structures are proposed. Finally, we discover a new mixed $\mathrm{CO}_{2}$ adsorption mechanism and show that carbamic acid formation is more prevalent in this materials class than previously believed. Our work paves the way for new investigations of carbon capture chemistry that can enable the design of improved materials.
\end{abstract}




\section{Introduction}

Carbon dioxide capture and storage is essential to reducing greenhouse gas emissions and meeting net-zero emissions targets. ${ }^{1,2}$ A range of technologies are under development to meet the need for more energy efficient carbon capture. One promising strategy to improve on traditional aqueous amine technology is to use solid adsorbent materials for capture. ${ }^{3-5} \mathrm{In}$ particular, installation of reactive amine or hydroxide functional groups within a porous scaffold such as a metal-organic framework or a porous silica brings about selective reactivity with $\mathrm{CO}_{2},{ }^{6-10}$ with the porous scaffold providing a large surface area for hosting the reactive groups while maintaining channels for $\mathrm{CO}_{2}$ transport. The increasingly complex adsorbent materials under consideration bring major challenges in the characterisation of new carbon capture chemistry, hindering the design of improved materials. ${ }^{4}$ Existing characterisation tools for understanding $\mathrm{CO}_{2}$ capture modes include single-crystal diffraction, ${ }^{11-13}$ powder diffraction, ${ }^{14}$ infra-red spectroscopy, ${ }^{6,10,15}$ X-ray absorption spectroscopy, ${ }^{16}$ and NMR spectroscopy, ${ }^{8,17-20}$ each of which has strengths and limitations in terms of the materials that can be studied and the information that can be obtained. Solid-state NMR spectroscopy is a promising tool for investigating $\mathrm{CO}_{2}$ binding modes in adsorbents as there is no requirement for long-range ordering and detailed information about the local structure and dynamics of the $\mathrm{CO}_{2}$ can be obtained. However, different $\mathrm{CO}_{2}$ adsorption products often give rise to very similar signals in the NMR spectrum and assigning these signals to specific $\mathrm{CO}_{2}$ binding modes remains very challenging. ${ }^{8,17-20}$

The most common experiment with the NMR approach is to dose the candidate adsorbent with ${ }^{13} \mathrm{CO}_{2}$ gas and perform ${ }^{13} \mathrm{C}$ magic angle spinning (MAS) NMR experiments. These experiments are relatively straightforward to perform, but often lead to ambiguous identification of the adsorption products. For amine-functionalised materials, the ${ }^{13} \mathrm{C}$ chemical shifts give poor differentiation between closely related ammonium carbamate, carbamic acid, and ammonium bicarbonate adsorption products, with the signals from these species showing considerable overlap. ${ }^{17,18}$ A similar problem arises for bicarbonate and carbonate products in hydroxide-based materials. ${ }^{20}$ The prediction of NMR parameters with density-functional theory (DFT) calculations ${ }^{21}$ can improve confidence in the structural assignments, and more advanced multi-nuclear NMR experiments can give improved differentiation between adsorption products. ${ }^{17,19,22}$ However, there remains a pressing need for the exploration of new NMR methods for understanding $\mathrm{CO}_{2}$ capture chemistry. ${ }^{23}$

A representative emerging class of $\mathrm{CO}_{2}$ adsorbents are amine-functionalised metal-organic frameworks. The framework $\mathrm{M}_{2}$ (dobpdc) (dobpdc $=4,4$ '-dioxidobiphenyl-3,3'-dicarboxylate) (Figure 1a) can straightforwardly be functionalised with amines to yield a family of (amine)$\mathrm{M}_{2}$ (dobpdc) adsorbents (Figure 1b). ${ }^{14}$ These adsorbents have large capacities for selective and reversible $\mathrm{CO}_{2}$ uptake, and the adsorption thermodynamics can be tuned by varying the amine, ${ }^{11,24-27}$ and the metal. ${ }^{14,28,29}$ Importantly, these materials generally display steep adsorption isotherms making them promising for a range of energy efficient carbon capture applications. $^{24,25}$ Initial characterisation of $\mathrm{CO}_{2}$ adsorption modes in these materials has revealed a rich chemistry, with three $\mathrm{CO}_{2}$ adsorption products proposed to date: (i) ammonium carbamate chains (Figure 1c), thought to be the dominant product in a range of 
variants, ${ }^{11}$ (ii) carbamic acid pairs (Figure 1d), identified in the Zn-based framework functionalised with the diamine dmpn (dmpn $=2$,2-dimethyl-1,3-diaminopropane) ${ }^{17,24}$ and (iii) a mixed adsorption product (Figure 1e) recently proposed for $(\mathrm{dmpn})-\mathrm{Mg}_{2}(\mathrm{dobpdc}){ }^{17}$ The adsorption thermodynamics of these three adsorption processes vary, motivating further characterisation to aid the design of metal-organic frameworks with the best $\mathrm{CO}_{2}$ capture performances.

Here we leverage the crystalline and tuneable family of (diamine) $-\mathrm{M}_{2}$ (dobpdc) adsorbents to perform a systematic computational exploration of solid-state NMR parameters for different $\mathrm{CO}_{2}$ adsorption products. We show that ${ }^{17} \mathrm{O}$ solid-state NMR spectroscopy is a powerful new probe of $\mathrm{CO}_{2}$ capture chemistry, providing unambiguous identification of carbamic acid formation and a detailed picture of the hydrogen-bonding environments.

(a)

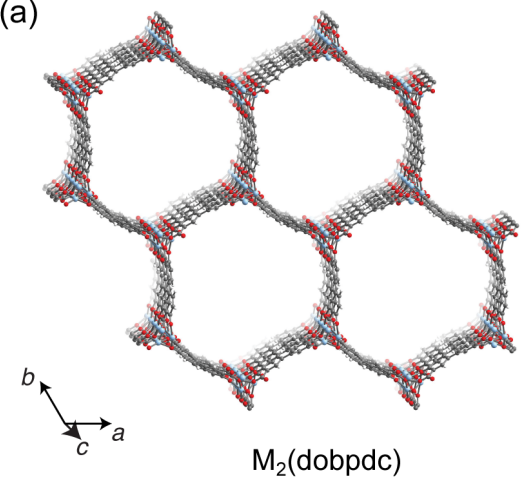

(b)

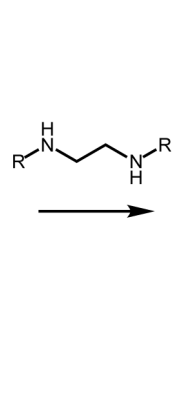

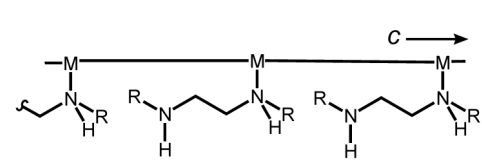

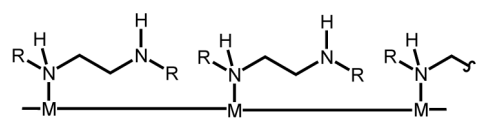

(amine) $-\mathrm{M}_{2}$ (dobpdc) (c)

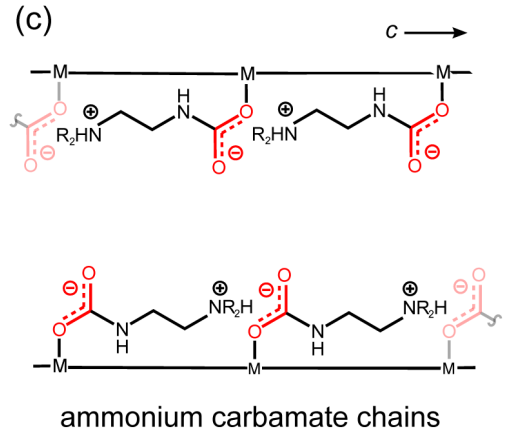

(d)

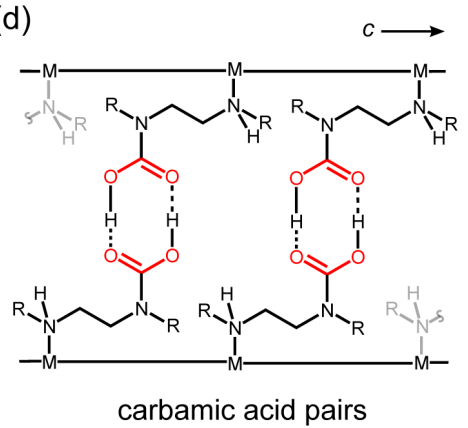

(e)

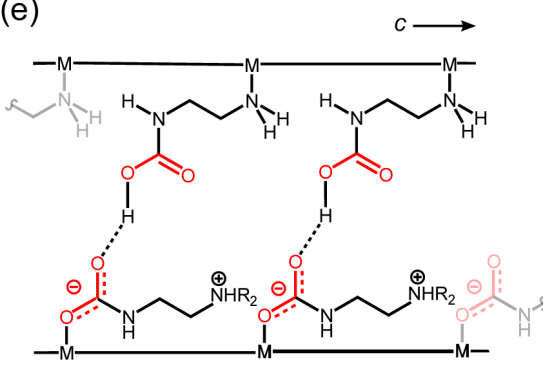

mixed adsorption structure

Figure 1. Structure and $\mathrm{CO}_{2}$ adsorption modes in (amine)- $\mathrm{M}_{2}$ (dobpdc) metal-organic frameworks. a) Structure of the metal organic framework $\mathrm{M}_{2}$ (dobpdc). b) Amine functionalisation yields (amine)- $\mathrm{M}_{2}$ (dobpdc). Upon exposure to $\mathrm{CO}_{2}$ various adsorption products can form. The most dominant adsorption products are: $\mathrm{c}$ ) ammonium carbamate chains, d) carbamic acid pairs and e) mixed ammonium carbamate - carbamic acid.

\section{Results and Discussion}

\section{Computational discovery of ${ }^{17} \mathrm{O}$ NMR as new probe of carbon capture}

The broad tunability of the diamine- $\mathrm{M}_{2}$ (dobpdc) family of materials and large number of available DFT-calculated adsorption structures presented an excellent opportunity to explore NMR parameters for differentiating $\mathrm{CO}_{2}$ adsorption products. To increase the diversity of 
structures explored, for select materials we explored not only the leading candidate adsorption product from previous studies, ${ }^{11,17}$ but also the other adsorption products in Figure 1 (see Table S1 for a list of studied materials). While ${ }^{13} \mathrm{C}$ NMR spectroscopy is the most commonly used tool for probing $\mathrm{CO}_{2}$ adsorption products, our DFT calculations show that poor differentiation of ammonium carbamate and carbamic acid binding modes is achieved by the ${ }^{13} \mathrm{C}$ chemical shifts (Figure S1a,b, Table S2). Better differentiation of products is achieved by considering the orientation dependence of the ${ }^{13} \mathrm{C}$ chemical shift (i.e., the chemical shift anisotropy), consistent with recent work on amine-functionalised silicas. ${ }^{19,23}$ However, in many cases carbamic acid and ammonium carbamate species still have similar ${ }^{13} \mathrm{C}$ NMR parameters (Figure S1c) because both the protonation state (ammonium carbamate chain or carbamic acid) and other hydrogen bonding interactions have an impact. These findings support the idea that alternative NMR probes beyond ${ }^{13} \mathrm{C}$ are needed to characterise $\mathrm{CO}_{2}$ adsorption modes with greater confidence.

We hypothesised that ${ }^{17} \mathrm{O}$ NMR spectroscopy would be a powerful probe ${ }^{30}$ of $\mathrm{CO}_{2}$ adsorption modes as the two oxygen atoms per $\mathrm{CO}_{2}$ molecule can have significantly different local environments depending on the adsorption product formed. The investigated adsorption products have a total of four main types of oxygen environment (Figure 2a). Ammonium carbamate chains have two oxygen environments with one of these bound to a metal ion, carbamic acid pairs have two oxygen environments corresponding to the carbonyl and hydroxyl oxygens, and the mixed adsorption mode features all four of these oxygen environments. Importantly, as ${ }^{17} \mathrm{O}$ is a spin $5 / 2$ nucleus, the resulting NMR spectra will be affected not only by the familiar chemical shift, $\left(\delta_{\text {iso }}\right)$, but also by the quadrupolar interaction, i.e., the interaction of the nuclear quadrupole moment with the surrounding electric field gradient, which is defined by the parameters $\mathrm{C}_{\mathrm{Q}}$ and $\eta_{\mathrm{Q}} \cdot{ }^{31} \mathrm{C}_{\mathrm{Q}}$ is the quadrupolar broadening defined as $\mathrm{C}_{\mathrm{Q}}=\mathrm{eQV}_{\mathrm{zz}} / \mathrm{h}$ and gives the magnitude of the interaction whilst $\eta_{\mathrm{Q}}$ measures the asymmetry of the interaction as $\eta_{\mathrm{Q}}=\left(\mathrm{V}_{\mathrm{yy}}-\mathrm{V}_{\mathrm{xx}} / \mathrm{V}_{\mathrm{zz}}\right)$, where $\mathrm{V}_{\mathrm{xx}}, \mathrm{V}_{\mathrm{yy}}$ and $\mathrm{V}_{\mathrm{zz}}$ are the principal components of the electric field gradient tensor, e is the electronic charge, $\mathrm{Q}$ is the nuclear quadrupole moment, and $\mathrm{h}$ is the Planck constant. By performing a ${ }^{17} \mathrm{O}$ MAS NMR experiment, $\delta_{\text {iso }}, C_{Q}$ and $\eta_{\mathrm{Q}}$ values can be obtained, therefore providing more information than ${ }^{13} \mathrm{C}$ NMR. 
(a)
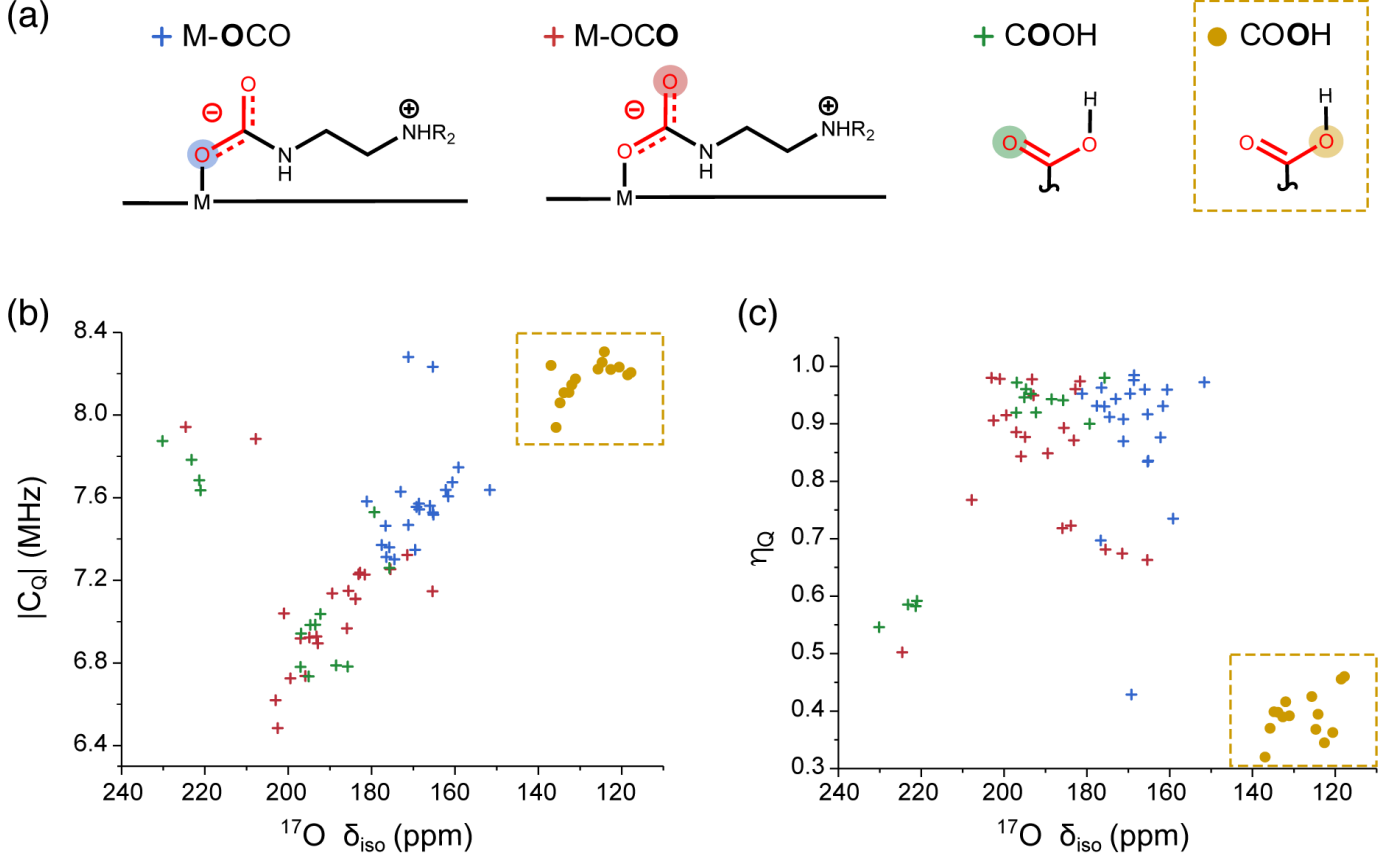

Figure 2. Computation exploration of ${ }^{17} \mathrm{O}$ NMR as a probe of adsorption modes. The calculated ${ }^{17} \mathrm{O}$ NMR parameters for the different oxygen environments present in the main adsorption structures. a) Plot of $C_{Q}$ vs $\delta_{\text {iso }}$ values for the various oxygen classes. b) Plot of $\eta_{\mathrm{Q}}$ vs $\delta_{\text {iso }}$ values for the various oxygen classes. c) Figures illustrating the classifications.

The calculated ${ }^{17} \mathrm{O}$ NMR parameters (Figure 2, Table S3) show that, broad clusters of data points are found for the various adsorption environments. Excitingly, the $\mathrm{OH}$ oxygens in carbamic acid species are differentiated from the other oxygen environments by a lower ${ }^{17} \mathrm{O}$ chemical shift, a higher $\mathrm{C}_{\mathrm{Q}}$ and a lower $\eta_{\mathrm{Q}}$ (marked with a yellow box). This differentiation is unambiguous compared to that found by ${ }^{13} \mathrm{C}$ NMR (Figure S1). For the non-protonated oxygen present in carbamic acids (green), two distinct groupings are seen, corresponding to oxygen in the mixed and carbamic acid pair environments, with the former having a higher shift and $C_{Q}$ but a lower $\eta_{\mathrm{Q}}$. Interestingly, the data also show that metal-bound carbamate oxygens (blue) are differentiated from free carbamate oxygens (red) by their generally lower chemical shifts. We note that some outliers are seen amongst the carbamate oxygens (blue and red), which correspond to ammonium carbamate chain structures with different hydrogen bonding arrangements. One of these is for $(\mathrm{R}, \mathrm{R})$-dach- $\mathrm{Mg}_{2}(\mathrm{dobpdc})$ (dach = trans-1,2diaminocyclohexane) where additional hydrogen bonding is seen between pairs of carbamate chains $^{32}$ and another outlier is for (i-2)- $\mathrm{Mg}_{2}$ (dobpdc) (i-2 = n-isopropylethylenediamine) where the proposed structure has a hydrogen bond between an amine and the oxygen next to the metal. ${ }^{11}$ Overall the DFT calculations show that ${ }^{17} \mathrm{O}$ NMR should provide good differentiation between adsorption products, especially for carbamic acid species. 


\section{Detection of different carbon capture products with ${ }^{17} \mathrm{O}$ NMR}

Motivated by the computational results, experimental ${ }^{17} \mathrm{O}$ NMR spectra were acquired for a series of representative adsorbents. First, a control experiment for activated $\mathrm{Mg}_{2}$ (dobpdc), i.e., with no amine functionalisation, revealed a relatively sharp resonance for physisorbed $\mathrm{CO}_{2}$ at 61.5 ppm (Figure 3a). ${ }^{33}$

(Ee-2) $-\mathrm{Mg}_{2}$ (dobpdc) $-\mathrm{CO}_{2}$ (ee-2 = N,Ndiethylethylenediamine) was then selected as the first amine functionalised sample, as previous characterisation has confidently assigned this material to form ammonium carbamate chains. ${ }^{11,17}$ Excitingly, the ${ }^{17} \mathrm{O}$ MAS NMR spectrum supports ammonium carbamate chain formation, with two oxygen environments of similar signal intensity observed (Figure 3b). Deconvolution of these two resonances, aided by a multiple-quantum MAS (MQMAS) spectrum (Figure S2), gave $\delta_{\text {iso }}, C_{Q}$ and $\eta_{Q}$ values in good agreement with DFT-calculated parameters for ammonium carbamate chains (Table 1). The agreement for six NMR parameters gives much greater confidence in the structural assignment than previous NMR work. $^{17}$ The spectrum for (ee-2)$\mathrm{Mg}_{2}$ (dobpdc) presented two additional peaks, one at $70.5 \mathrm{ppm}$ assigned to physisorbed $\mathrm{CO}_{2}$ and a smaller second peak at around $-22 \mathrm{ppm}$. The identity of this minor peak is unknown, though it potentially arises from $\mathrm{CO}_{2}$ reacting with defects in the metal-organic framework, since this signal was also weakly observed (a) $\mathrm{Mg}_{2}$ (dobpdc)
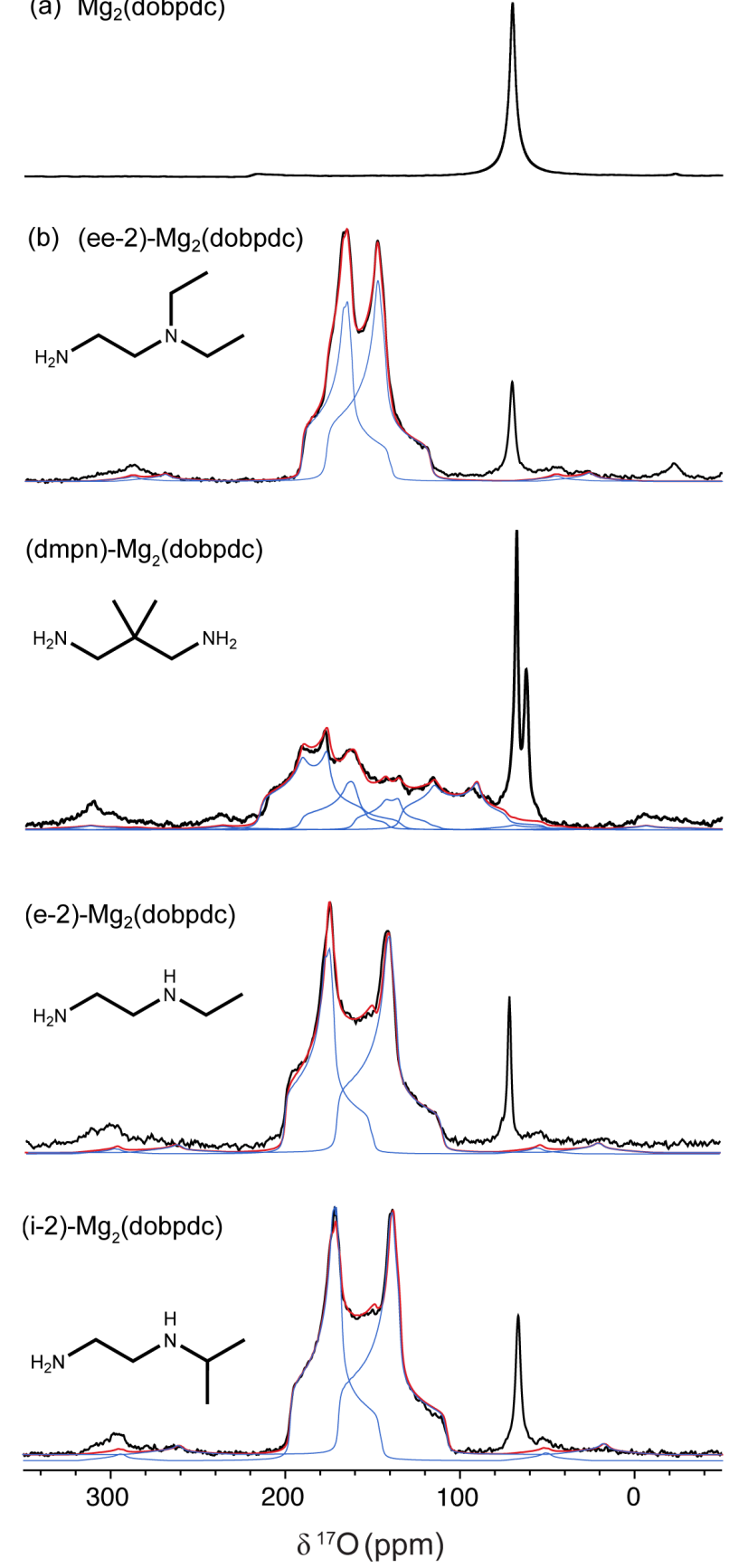

Figure $3 .{ }^{17} \mathrm{O}$ MAS NMR spectra of representative ${ }^{17} \mathrm{O}$ enriched $\mathrm{CO}_{2}$-dosed adsorbents. a) The ${ }^{17} \mathrm{O}$ MAS NMR (23.5 T, $20 \mathrm{kHz}$ MAS) of activated $\mathrm{Mg}_{2}$ (dobpdc) i.e. diamine-free MOF b) The MAS ${ }^{17} \mathrm{O}$ NMR spectra $(20.0 \mathrm{~T}$, $14 \mathrm{kHz}$ MAS) of the four investigated diaminefunctionalised frameworks. Black, red, blue lines show the experimental data, the fit, and the deconvoluted peaks, respectively.

in the spectrum of unfunctionalized $\mathrm{Mg}_{2}$ (dobpdc). Finally, the ${ }^{17} \mathrm{O}$ NMR spectrum could be acquired rapidly, with an acquisition time of $\sim 27$ minutes, and with an estimated cost of ${ }^{17} \mathrm{O}$ enriched $\mathrm{CO}_{2}$ gas of $£ 50$ per sample, which could be reduced in future by optimising the gas dosing line used to prepare samples. 
Table 1. Overview of the experimental and DFT-calculated ${ }^{17} \mathrm{O}$ NMR parameters for the various diaminefunctionalised frameworks adsorbing $\mathrm{CO}_{2}$ to form carbamate chains. The DFT structures used for the different compounds correspond to those in Figure S5.

\begin{tabular}{|c|c|c|c|c|}
\hline Compound & Amine Structure & $\delta^{17} \mathrm{O}(\mathrm{ppm})$ & $\mathrm{C}_{\mathrm{Q}}(\mathrm{MHz})$ & $\eta_{\mathrm{Q}}$ \\
\hline & & Experiment (DFT) & Experiment (DFT) & Experiment (DFT) \\
\hline \multirow[t]{2}{*}{$($ ee- 2$)-\mathrm{Mg}_{2}$ (dobpdc) } & $\mathrm{H}_{2} \mathrm{~N}$ & M-OCO: 177 (169) & $6.8(7.4)$ & $1.0(1.0)$ \\
\hline & & M-OCO: 191 (186) & $6.4(7.0)$ & $0.8(0.7)$ \\
\hline \multirow[t]{2}{*}{$(\mathrm{i}-2)-\mathrm{Mg}_{2}(\mathrm{dobpdc})$} & & M-OCO: 171 (169) & $6.9(7.6)$ & $1.0(0.4)$ \\
\hline & & M-OCO: 197 (224) & $6.3(7.9)$ & $0.9(0.5)$ \\
\hline \multirow[t]{2}{*}{$(\mathrm{e}-2)-\mathrm{Mg}_{2}(\mathrm{dobpdc})$} & & M-OCO: 172 (174) & $6.9(7.3)$ & $0.9(0.9)$ \\
\hline & & M-OCO: 202 (175) & $6.5(7.3)$ & $0.9(0.7)$ \\
\hline
\end{tabular}

(Dmpn)- $\mathrm{Mg}_{2}$ (dobpdc) (dmpn = 2,2-dimethyl-1,3-diaminopropane) is hypothesised to adsorb $\mathrm{CO}_{2}$ via a mixed adsorption mechanism (Figure $\left.1 \mathrm{e}\right)^{17}$ and is therefore an ideal candidate to assess whether ${ }^{17} \mathrm{O}$ NMR spectroscopy can be used to determine more complex binding modes. The ${ }^{17} \mathrm{O}$ MAS NMR spectrum (Figure 3b, Figure S2,3) shows a broad lineshape with multiple overlapping signals, which could be deconvoluted to reveal four oxygen environments consistent with $\mathrm{CO}_{2}$ binding via the mixed adsorption mechanism. To gain increased confidence in the extracted NMR parameters, we simultaneously fitted data from two magnetic field strengths (Figures S4). The 12 measured NMR parameters are consistent with the DFT-calculated values for the mixed mechanism (Table 2), and provide important support for this recently hypothesised adsorption mode. Most notably, the experimental results show a clear carbamic acid $\mathrm{OH}$ resonance, which stands out with a lower chemical shift, larger $C_{Q}$ and a lower $\eta_{Q}$ as predicted by the DFT calculations (see Figure S3 for spectrum at $23.5 \mathrm{~T}$, where the acid resonance is more clearly resolved). Finally, we note that for dmpn- $\mathrm{Mg}_{2}$ (dobpdc), two resonances are observed for physisorbed $\mathrm{CO}_{2}$ at 62.7 and 68.1 ppm, with the origin of these currently unclear. Summarising, the experiments on (dmpn)$\mathrm{Mg}_{2}$ (dobpdc) showcase the excellent ability of ${ }^{17} \mathrm{O}$ NMR to determine complex adsorption modes and to distinguish ammonium carbamate and carbamic acid species. 
Table 2. The experimental and DFT calculated ${ }^{17} \mathrm{O}$ parameters for dmpn- $\mathrm{Mg}_{2}$ (dobpdc). DFT calculations are for the mixed carbamic acid - ammonium carbamate adsorption structure. The experimental fit was obtained by simultaneously fitting data on two independent samples at two field strengths (20.0 and $23.5 \mathrm{~T})$ using ssnake software $^{34}$, see Figure S4.

\begin{tabular}{|c|c|c|c|c|}
\hline \multirow[t]{2}{*}{ Compound } & Amine Structure & $\delta{ }^{17} \mathrm{O}(\mathrm{ppm})$ & $\mathrm{C}_{\mathrm{Q}}(\mathrm{MHz})$ & $\eta_{\mathrm{Q}}$ \\
\hline & & Experiment (DFT) & Experiment (DFT) & Experiment (DFT) \\
\hline \multirow[t]{4}{*}{$(\mathrm{dmpn})-\mathrm{Mg}_{2}(\mathrm{dobpdc})$} & & M-OCO: 168 (166) & $6.9(7.6)$ & $0.8(1.0)$ \\
\hline & & M-OCO: 194 (183) & $7.2(7.2)$ & $0.7(0.9)$ \\
\hline & & COOH: 217 (230) & $7.6(7.9)$ & $0.6(0.5)$ \\
\hline & & СООН: 137 (131) & $8.0(8.2)$ & $0.3(0.4)$ \\
\hline
\end{tabular}

$\mathrm{CO}_{2}$-dosed (i-2)- $\mathrm{Mg}_{2}$ (dobpdc), (i-2 = N-isopropylethylenediamine), and (e-2)- $\mathrm{Mg}_{2}$ (dobpdc), (e-2 $=N$-ethylethylenediamine), were then investigated to further test the robustness of ${ }^{17} \mathrm{O}$ NMR in identifying $\mathrm{CO}_{2}$ adsorption products. The ${ }^{17} \mathrm{O}$ MAS NMR spectra of these compounds closely resemble that of (ee-2)- $\mathrm{Mg}_{2}$ (dobpdc), consistent with ammonium carbamate chain formation (Figure 3b). Interestingly, discrepancies arise when comparing the experimental and DFT-calculated NMR parameters for (e-2)- $\mathrm{Mg}_{2}$ (dobpdc) and especially (i2) $-\mathrm{Mg}_{2}$ (dobpdc) (Table 1), suggesting that the DFT-proposed models are inaccurate. The models for (ee-2) $-\mathrm{Mg}_{2}$ (dobpdc) and (i-2) $-\mathrm{Mg}_{2}$ (dobpdc) (based on single crystal diffraction structures for the analogous zinc frameworks) ${ }^{11}$ show important differences in their hydrogen bonding arrangements, with a hydrogen bond formed from the ammonium to the "free" carbamate oxygen for the ee-2 variant (Figure S5a), and the metal bound carbamate oxygen for the i-2 variant (Figure S5b). In the DFT model for (e-2)- $\mathrm{Mg}_{2}$ (dobpdc) additional hydrogen bonding interactions are also present. The findings that (i) the experimental ${ }^{17} \mathrm{O} \mathrm{NMR}$ parameters for (i-2) $-\mathrm{Mg}_{2}$ (dobpdc) and (e-2) $-\mathrm{Mg}_{2}$ (dobpdc) show poor agreement with the DFT values, and (ii) the spectra closely resemble that for (ee-2)- $\mathrm{Mg}_{2}$ (dobpdc), challenge these alternative hydrogen bonding arrangements and suggests that all structures instead have hydrogen bonds solely between the ammonium proton and the "free" oxygen as in (ee-2)$\mathrm{Mg}_{2}$ (dobpdc) (Figure S5a). DFT parameters for an improved (e-2)- $\mathrm{Mg}_{2}$ (dobpdc) model are shown in Figure S6 and Table S4, with our findings further highlighting the excellent ability of ${ }^{17} \mathrm{O}$ NMR experiments to differentiate subtly different $\mathrm{CO}_{2}$ adsorption products.

\section{Observation of carbamic acid formation in (ii-2)- $\mathrm{Mg}_{2}$ (dobpdc)}

As a final test of ${ }^{17} \mathrm{O}$ NMR as a probe of carbon capture mechanisms, we examined the capture mode of (ii-2) $-\mathrm{Mg}_{2}(\mathrm{dobpdc})$ for the first time (ii-2 $=\mathrm{N}, \mathrm{N}$ diisopropylethylenediamine). We initially assumed this material would form ammonium carbamate chains upon $\mathrm{CO}_{2}$ adsorption, as in the related material (ee-2)- $\mathrm{Mg}_{2}$ (dobpdc). Excitingly, the ${ }^{17} \mathrm{O}$ MAS NMR spectrum acquired at $23.5 \mathrm{~T}$ (Figure 4a) instead reveals a clear carbamic acid resonance $\left(\delta_{\text {iso }}=125.8 \mathrm{ppm}, \mathrm{C}_{\mathrm{Q}}=7.99 \mathrm{MHz}, \eta_{\mathrm{Q}}=0.43\right.$, see carbamic acid $\mathrm{OH}$ groups in Figure 2). This peak was also seen in a spectrum on an independent sample at 20.0 $\mathrm{T}$ (Figure S7). Furthermore, the integral of the carbamic acid peak relative to the rest of the peaks is 1:3.34, likely indicating the presence of four oxygen environments which would be expected in a mixed ammonium carbamate - carbamic acid adsorption structure. The NMR 
spectrum seen is different from that of dmpn- $\mathrm{Mg}_{2}(\mathrm{dobpdc})$ (Figure S3), hinting that this is a different mixed mechanism to that previously reported (Figure 1e). The left-hand overlapped feature is harder to deconvolute, likely consisting of three oxygen environments at similar shifts.

(a) (ii-2)- $\mathrm{Mg}_{2}($ dobpdc)

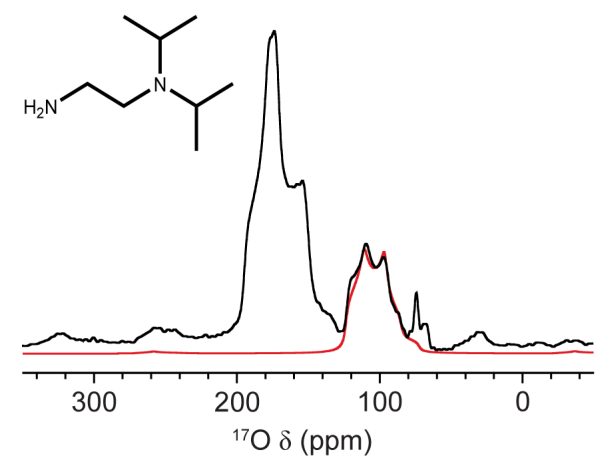

(c)

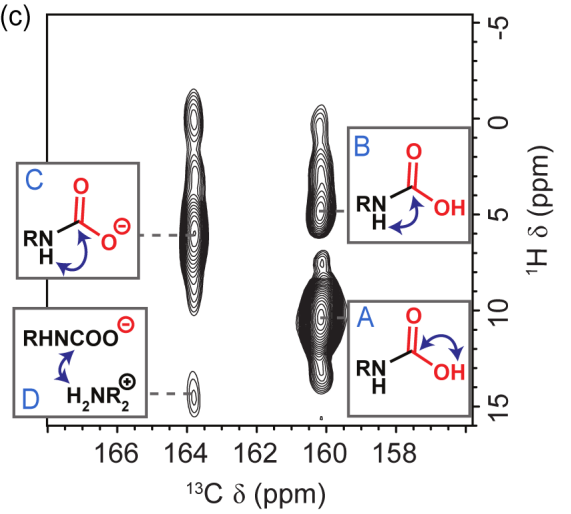

(b)

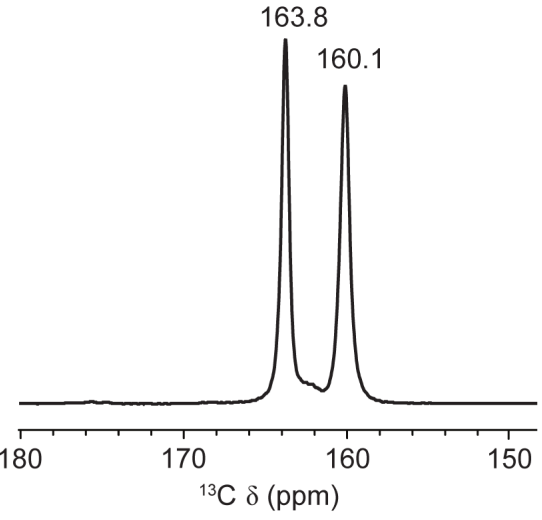

(d)
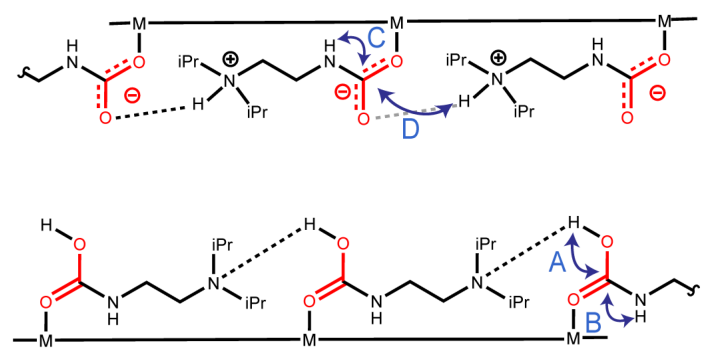

Figure 4. A new mixed $\mathbf{C O}_{2}$ adsorption mode for (ii-2)- $\mathbf{M g}_{\mathbf{2}}$ (dobpdc) (a) ${ }^{17} \mathrm{O}$ NMR (23.5 T, $20 \mathrm{kHz}$ MAS) spectrum of (ii-2)- $\mathrm{Mg}_{2}$ (dobpdc) dosed with ${ }^{17} \mathrm{O}-\mathrm{CO}_{2}$. The red line shows the deconvolution of a single oxygen environment assigned to a carbamic acid $\mathrm{OH}$ group. (b) MAS ${ }^{13} \mathrm{C}$ NMR (16.4 T, $15 \mathrm{kHz}$ MAS) spectra acquired by cross polarization (contact time $1 \mathrm{~ms}$ ) for ii-2- $\mathrm{Mg}_{2}$ (dobpdc) $-\mathrm{CO}_{2}$ dosed at $950 \mathrm{mbar}{ }^{13} \mathrm{CO}_{2}$. (c) ${ }^{1} \mathrm{H} \rightarrow{ }^{13} \mathrm{C}$ heteronuclear correlation (contact time $100 \mu \mathrm{s}$ ) spectrum, with key correlation peaks indicated by blue arrows on hypothesised Lewis structures. (d) Lewis structure of the DFT-calculated proposed structure. Key ${ }^{1} \mathrm{H}-{ }^{13} \mathrm{C}$ correlation groups are shown.

Investigating this adsorption mechanism further, a ${ }^{13} \mathrm{C}$ MAS NMR spectrum (Figure $4 \mathrm{~b}$ ) showed two chemisorbed $\mathrm{CO}_{2}$ resonances at 163.8 and $160.1 \mathrm{ppm}$, assignable to ammonium carbamate and carbamic acid, respectively, and consistent with the observations from ${ }^{17} \mathrm{O}$ NMR. ${ }^{17}$ The ${ }^{13} \mathrm{C}$ peaks had relative intensities of 1:0.9 (quantitative NMR) further supporting a mixed adsorption mechanism consisting of two different $\mathrm{CO}_{2}$ environments. Support for the ${ }^{13} \mathrm{C}$ peak assignments is provided by a $2 \mathrm{D}{ }^{1} \mathrm{H}-{ }^{13} \mathrm{C}$ heteronuclear correlation experiment with a short contact time (Figure 4c), which reveals ${ }^{1} \mathrm{H}-{ }^{13} \mathrm{C}$ correlations for hydrogens nearby the carbons of the chemisorbed $\mathrm{CO}_{2}$. Most importantly, the ${ }^{13} \mathrm{C}$ resonance at $160.1 \mathrm{ppm}$ shows a strong correlation with a ${ }^{1} \mathrm{H}$ resonance at $10.3 \mathrm{ppm}$, assigned to a carbamic acid $\mathrm{COOH}$ group. ${ }^{17}$ Strong $\mathrm{N}-\mathrm{H}$ correlations are observed for both resonances supporting reaction with $\mathrm{CO}_{2}$ at the primary amine in both cases. The $163.8 \mathrm{ppm}{ }^{13} \mathrm{C}$ resonance also shows a weak correlation with an ammonium group at $14.6 \mathrm{ppm}$, with the ${ }^{1} \mathrm{H}$ chemical shift of this species 
comparable to those observed previously for tertiary ammonium groups in ammonium carbamate chains for related materials. ${ }^{17}$

Finally, an adsorption structure was proposed to explain the above results (Figure 4d). The proposed structure features a mixture of ammonium carbamate chains and carbamic acid chains, with $\mathrm{CO}_{2}$ insertion occurring between the metal-amine bond in both cases. The relative signal ratios from ${ }^{17} \mathrm{O}$ and ${ }^{13} \mathrm{C}$ NMR suggests that these two chain variants are present in similar proportions and hence have similar free energies. To check the proposed model, NMR parameters were obtained from DFT (Table 3) and showed a good agreement for the $\mathrm{OH}$ peak corresponding to carbamic acid, however further work is needed to confidently assign the environments of the other resulting three peaks. Importantly, ii- 2 is only the second diamine variant (after dmpn) that has been shown to form carbamic acid. In common with dmpn, ii-2 possesses bulky alkyl groups, suggesting that steric bulk is an important handle for tuning adsorption chemistry in amine-functionalised metal-organic frameworks. Overall, these experiments highlight the power of ${ }^{17} \mathrm{O}$ NMR spectroscopy to uncover adsorption chemistry in new materials, and we envisage the application of these methods to a wide range of $\mathrm{CO}_{2}$ capture materials.

Table 3. The experimental and DFT calculated ${ }^{17} \mathrm{O}$ parameters of (ii-2)- $\mathrm{Mg}_{2}$ (dobpdc). DFT calculations are for the mixed carbamate chain structure described in Figure $4 \mathrm{~d}$. The experimental fit was obtained by simultaneously fitting data on two independent samples at two field strengths $(20.0$ and $23.5 \mathrm{~T})$ using ssnake software $^{34}$, see Figure S8.

\begin{tabular}{|c|c|c|c|c|}
\hline \multirow[t]{2}{*}{ Compound } & \multirow[t]{2}{*}{ Amine Structure } & $\delta^{17} \mathrm{O}(\mathrm{ppm})$ & $\mathrm{C}_{\mathrm{Q}}(\mathrm{MHz})$ & $\eta_{\mathrm{Q}}$ \\
\hline & & Experiment (DFT) & $\begin{array}{c}\text { Experiment } \\
\text { (DFT) }\end{array}$ & Experiment (DFT) \\
\hline \multirow[t]{4}{*}{$(\mathrm{ii}-2)-\mathrm{Mg}_{2}(\mathrm{dobpdc})$} & & M-OCO: 185 (176) & $7.5(7.4)$ & $0.9(0.9)$ \\
\hline & & M-OCO: 198 (203) & $7.5(6.6)$ & $1.0(1.0)$ \\
\hline & & М-СООН: 196 (179) & $6.8(7.5)$ & $0.8(0.9)$ \\
\hline & & М-СOOH: 126 (137) & $8.3(8.2)$ & $0.5(0.3)$ \\
\hline
\end{tabular}

\section{Summary}

In summary, ${ }^{17} \mathrm{O}$ NMR has been shown to be an excellent probe of different $\mathrm{CO}_{2}$ adsorption products in amine functionalised metal-organic framework adsorbents. In particular, ${ }^{17} \mathrm{O}$ NMR can differentiate between ammonium carbamate chains and carbamic acids in a wide range of materials with much greater confidence than ${ }^{13} \mathrm{C} \mathrm{NMR}$, which has previously been the nucleus of choice for studying $\mathrm{CO}_{2}$ capture chemistry and has led to ambiguous structural assignments. Our measurements provide new support for ammonium carbamate chain formation in a series of (amine) $-\mathrm{Mg}_{2}$ (dobpdc) variants, and also provide strong evidence for a recently proposed mixed ammonium carbamate - carbamic acid mechanism for the material (dmpn) $-\mathrm{Mg}_{2}$ (dobpdc). We finally reveal carbamic acid formation in a previously poorly studied adsorbent, (ii-2)- $\mathrm{Mg}_{2}$ (dobpdc), highlighting the prevalence of carbamic acid in frameworks with bulky amine groups. In the future ${ }^{17} \mathrm{O}$ NMR spectroscopy will be extended 
to a range of carbon capture technologies and will ultimately enable the design of improved materials that can help tackle the climate crisis.

\section{References}

(1) Committee on Climate Change. Net Zero: The UK's Contribution to Stopping Global Warming. Committee on Climate Change 2019, No. May.

(2) Masson-Delmotte, V.; Zhai, P.; Pörtner, H.-O.; Roberts, D.; Skea, J.; Shukla, P. R.; Pirani, A.; Moufouma-Okia, W.; Péan, C.; Pidcock France, R.; Connors, S.; Matthews, J. B. R.; Chen, Y.; Zhou, X.; Gomis, M. I.; Lonnoy, E.; Maycock, T.; Tignor, M.; Waterfield, T. Summary for Policymakers. Global Warming of $1.5^{\circ} \mathrm{C}$. An IPCC Special Report on the Impacts of Global Warming of $1.5^{\circ} \mathrm{C}$ above Pre-Industrial Levels.; 2018.

(3) Siegelman, R. L.; Kim, E. J.; Long, J. R. Porous Materials for Carbon Dioxide Separations. Nature Materials. 2021. https://doi.org/10.1038/s41563-021-01054-8.

(4) Forse, A. C.; Milner, P. J. New Chemistry for Enhanced Carbon Capture: Beyond Ammonium Carbamates. Chemical Science. 2021. https://doi.org/10.1039/d0sc06059c.

(5) Choi, S.; Drese, J. H.; Jones, C. W. Adsorbent Materials for Carbon Dioxide Capture from Large Anthropogenic Point Sources. ChemSusChem. 2009. https://doi.org/10.1002/cssc.200900036.

(6) Liao, P. Q.; Chen, H.; Zhou, D. D.; Liu, S. Y.; He, C. T.; Rui, Z.; Ji, H.; Zhang, J. P.; Chen, X. M. Monodentate Hydroxide as a Super Strong yet Reversible Active Site for CO2 Capture from High-Humidity Flue Gas. Energy and Environmental Science 2015, 8 (3). https://doi.org/10.1039/c4ee02717e.

(7) Bollini, P.; Didas, S. A.; Jones, C. W. Amine-Oxide Hybrid Materials for Acid Gas Separations. Journal of Materials Chemistry 2011, 21 (39). https://doi.org/10.1039/c1jm12522b.

(8) Flaig, R. W.; Osborn Popp, T. M.; Fracaroli, A. M.; Kapustin, E. A.; Kalmutzki, M. J.; Altamimi, R. M.; Fathieh, F.; Reimer, J. A.; Yaghi, O. M. The Chemistry of CO2 Capture in an Amine-Functionalized Metal-Organic Framework under Dry and Humid Conditions. Journal of the American Chemical Society 2017, 139 (35). https://doi.org/10.1021/jacs.7b06382.

(9) McDonald, T. M.; D’Alessandro, D. M.; Krishna, R.; Long, J. R. Enhanced Carbon Dioxide Capture upon Incorporation of N,N'- Dimethylethylenediamine in the Metal-Organic Framework CuBTTri. Chemical Science 2011, 2 (10). https://doi.org/10.1039/c1 sc00354b.

(10) Bien, C. E.; Chen, K. K.; Chien, S. C.; Reiner, B. R.; Lin, L. C.; Wade, C. R.; Ho, W. S. W. Bioinspired Metal-Organic Framework for Trace CO2 Capture. Journal of the American Chemical Society 2018, 140 (40). https://doi.org/10.1021/jacs.8b06109.

(11) Siegelman, R. L.; McDonald, T. M.; Gonzalez, M. I.; Martell, J. D.; Milner, P. J.; Mason, J. A.; Berger, A. H.; Bhown, A. S.; Long, J. R. Controlling Cooperative CO2 Adsorption in DiamineAppended Mg2(Dobpdc) Metal-Organic Frameworks. Journal of the American Chemical Society 2017, 139 (30). https://doi.org/10.1021/jacs. 7b05858.

(12) Bhatt, P. M.; Belmabkhout, Y.; Cadiau, A.; Adil, K.; Shekhah, O.; Shkurenko, A.; Barbour, L. J.; Eddaoudi, M. A Fine-Tuned Fluorinated MOF Addresses the Needs for Trace CO2 Removal and Air Capture Using Physisorption. Journal of the American Chemical Society 2016, 138 (29). https://doi.org/10.1021/jacs.6b05345. 
(13) Williams, N. J.; Seipp, C. A.; Brethomé, F. M.; Ma, Y. Z.; Ivanov, A. S.; Bryantsev, V. S.; Kidder, M. K.; Martin, H. J.; Holguin, E.; Garrabrant, K. A.; Custelcean, R. CO2 Capture via Crystalline Hydrogen-Bonded Bicarbonate Dimers. Chem 2019, 5 (3). https://doi.org/10.1016/j.chempr.2018.12.025.

(14) McDonald, T. M.; Mason, J. A.; Kong, X.; Bloch, E. D.; Gygi, D.; Dani, A.; Crocellà, V.; Giordanino, F.; Odoh, S. O.; Drisdell, W. S.; Vlaisavljevich, B.; Dzubak, A. L.; Poloni, R.; Schnell, S. K.; Planas, N.; Lee, K.; Pascal, T.; Wan, L. F.; Prendergast, D.; Neaton, J. B.; Smit, B.; Kortright, J. B.; Gagliardi, L.; Bordiga, S.; Reimer, J. A.; Long, J. R. Cooperative Insertion of CO2 in Diamine-Appended Metal-Organic Frameworks. Nature 2015, 519 (7543). https://doi.org/10.1038/nature14327.

(15) Didas, S. A.; Sakwa-Novak, M. A.; Foo, G. S.; Sievers, C.; Jones, C. W. Effect of Amine Surface Coverage on the Co-Adsorption of $\mathrm{CO} 2$ and Water: Spectral Deconvolution of Adsorbed Species. Journal of Physical Chemistry Letters 2014, 5 (23). https://doi.org/10.1021/jz502032c.

(16) Drisdell, W. S.; Poloni, R.; McDonald, T. M.; Pascal, T. A.; Wan, L. F.; Pemmaraju, C. das; Vlaisavljevich, B.; Odoh, S. O.; Neaton, J. B.; Long, J. R.; Prendergast, D.; Kortright, J. B. Probing the Mechanism of CO2 Capture in Diamine-Appended Metal-Organic Frameworks Using Measured and Simulated X-Ray Spectroscopy. Physical Chemistry Chemical Physics 2015, 17 (33). https://doi.org/10.1039/c5cp02951a.

(17) Forse, A. C.; Milner, P. J.; Lee, J. H.; Redfearn, H. N.; Oktawiec, J.; Siegelman, R. L.; Martell, J. D.; Dinakar, B.; Porter-Zasada, L. B.; Gonzalez, M. I.; Neaton, J. B.; Long, J. R.; Reimer, J. A. Elucidating $\mathrm{CO} 2$ Chemisorption in Diamine-Appended Metal-Organic Frameworks. Journal of the American Chemical Society 2018, 140 (51). https://doi.org/10.1021/jacs.8b10203.

(18) Chen, C. H.; Shimon, D.; Lee, J. J.; Mentink-Vigier, F.; Hung, I.; Sievers, C.; Jones, C. W.; Hayes, S. E. The "Missing" Bicarbonate in CO 2 Chemisorption Reactions on Solid Amine Sorbents. Journal of the American Chemical Society 2018, 140 (28). https://doi.org/10.1021/jacs.8b04520.

(19) Mafra, L.; Čendak, T.; Schneider, S.; Wiper, P. v.; Pires, J.; Gomes, J. R. B.; Pinto, M. L. Structure of Chemisorbed CO2 Species in Amine-Functionalized Mesoporous Silicas Studied by Solid-State NMR and Computer Modeling. Journal of the American Chemical Society 2017, 139 (1). https://doi.org/10.1021/jacs.6b11081.

(20) Yang, H.; Singh, M.; Schaefer, J. Humidity-Swing Mechanism for CO2 Capture from Ambient Air. Chemical Communications 2018, 54 (39). https://doi.org/10.1039/c8cc02109k.

(21) Bonhomme, C.; Gervais, C.; Babonneau, F.; Coelho, C.; Pourpoint, F.; Azaïs, T.; Ashbrook, S. E.; Griffin, J. M.; Yates, J. R.; Mauri, F.; Pickard, C. J. First-Principles Calculation of NMR Parameters Using the Gauge Including Projector Augmented Wave Method: A Chemists Point of View. Chemical Reviews. 2012. https://doi.org/10.1021/cr300108a.

(22) Chen, C. H.; Shimon, D.; Lee, J. J.; Didas, S. A.; Mehta, A. K.; Sievers, C.; Jones, C. W.; Hayes, S. E. Spectroscopic Characterization of Adsorbed 13CO2 on 3-AminopropylsilylModified SBA15 Mesoporous Silica. Environmental Science and Technology 2017, 51 (11). https://doi.org/10.1021/acs.est.6b06605.

(23) Čendak, T.; Sequeira, L.; Sardo, M.; Valente, A.; Pinto, M. L.; Mafra, L. Detecting Proton Transfer in CO2 Species Chemisorbed on Amine-Modified Mesoporous Silicas by Using 13C 
NMR Chemical Shift Anisotropy and Smart Control of Amine Surface Density. Chemistry - A European Journal 2018, 24 (40). https://doi.org/10.1002/chem.201800930.

(24) Milner, P. J.; Siegelman, R. L.; Forse, A. C.; Gonzalez, M. I.; Runčevski, T.; Martell, J. D.; Reimer, J. A.; Long, J. R. A Diaminopropane-Appended Metal-Organic Framework Enabling Efficient CO2 Capture from Coal Flue Gas via a Mixed Adsorption Mechanism. Journal of the American Chemical Society 2017, 139 (38). https://doi.org/10.1021/jacs.7b07612.

(25) Kim, E. J.; Siegelman, R. L.; Jiang, H. Z. H.; Forse, A. C.; Lee, J. H.; Martell, J. D.; Milner, P. J.; Falkowski, J. M.; Neaton, J. B.; Reimer, J. A.; Weston, S. C.; Long, J. R. Cooperative Carbon Capture and Steam Regeneration with Tetraamine-Appended Metal-Organic Frameworks. Science 2020, 369 (6502). https://doi.org/10.1126/science.abb3976.

(26) Lee, W. R.; Hwang, S. Y.; Ryu, D. W.; Lim, K. S.; Han, S. S.; Moon, D.; Choi, J.; Hong, C. S. Diamine-Functionalized Metal-Organic Framework: Exceptionally High CO 2 Capacities from Ambient Air and Flue Gas, Ultrafast CO2 Uptake Rate, and Adsorption Mechanism. Energy and Environmental Science 2014, 7 (2). https://doi.org/10.1039/c3ee42328j.

(27) Lee, W. R.; Jo, H.; Yang, L. M.; Lee, H.; Ryu, D. W.; Lim, K. S.; Song, J. H.; Min, D. Y.; Han, S. S.; Seo, J. G.; Park, Y. K.; Moon, D.; Hong, C. S. Exceptional CO2 Working Capacity in a Heterodiamine-Grafted Metal-Organic Framework. Chemical Science 2015, 6 (7). https://doi.org/10.1039/c5sc01191d.

(28) Zheng, X.; Zhang, H.; Yang, L. M.; Ganz, E. CO2Adsorption Properties of a N, NDiethylethylenediamine-Appended M2(Dobpdc) Series of Materials and Their Detailed Microprocess. Crystal Growth and Design 2021, 21 (4). https://doi.org/10.1021/acs.cgd.1c00096.

(29) Lee, J. H.; Siegelman, R. L.; Maserati, L.; Rangel, T.; Helms, B. A.; Long, J. R.; Neaton, J. B. Enhancement of $\mathrm{CO} 2$ Binding and Mechanical Properties upon Diamine Functionalization of M2(Dobpdc) Metal-Organic Frameworks. Chemical Science 2018, 9 (23). https://doi.org/10.1039/c7sc05217k.

(30) Ashbrook, S. E.; Davis, Z. H.; Morris, R. E.; Rice, C. M. 17O NMR Spectroscopy of Crystalline Microporous Materials. Chemical Science. 2021. https://doi.org/10.1039/d1sc00552a.

(31) Wu, G. 17O NMR Studies of Organic and Biological Molecules in Aqueous Solution and in the Solid State. Progress in Nuclear Magnetic Resonance Spectroscopy. 2019. https://doi.org/10.1016/j.pnmrs.2019.06.002.

(32) Martell, J. D.; Porter-Zasada, L. B.; Forse, A. C.; Siegelman, R. L.; Gonzalez, M. I.; Oktawiec, J.; Runčevski, T.; Xu, J.; Srebro-Hooper, M.; Milner, P. J.; Colwell, K. A.; Autschbach, J.; Reimer, J. A.; Long, J. R. Enantioselective Recognition of Ammonium Carbamates in a Chiral Metal-Organic Framework. Journal of the American Chemical Society 2017, 139 (44). https://doi.org/10.1021/jacs.7b09983.

(33) Wang, W.; Waang, W. D.; Lucier, B. E. G.; Terskikh, V. v.; Huang, Y. Wobbling and Hopping: Studying Dynamics of CO2 Adsorbed in Metal-Organic Frameworks via 170 SolidState NMR. Journal of Physical Chemistry Letters 2014, 5 (19). https://doi.org/10.1021/jz501729d.

(34) van Meerten, S. G. J.; Franssen, W. M. J.; Kentgens, A. P. M. SsNake: A Cross-Platform Open-Source NMR Data Processing and Fitting Application. Journal of Magnetic Resonance 2019, 301, 56-66. https://doi.org/10.1016/J.JMR.2019.02.006. 


\section{Methods}

\section{Materials}

All of the chemicals used in this project were purchased from commercial suppliers and were used without further purification. The ligand 4,4'-dihydroxy-[1,1'-biphenyl]-3,3'-dicarboxylic acid $\left(\mathrm{H}_{4}\right.$ dobpdc) was purchased from Hangzhou Trylead Chemical Technology. ${ }^{17} \mathrm{O}$-enriched $\mathrm{CO}_{2}$ gas was purchased from ICON/Berry \& Associates, Inc, with approximately 20 atom \% ${ }^{17} \mathrm{O}$.

\section{$\mathrm{Mg}_{2}$ (dobpdc) Synthesis}

$\mathrm{Mg}_{2}$ (dobpdc) was synthesised according to a previously reported procedure. ${ }^{1}$ $\mathrm{Mg}\left(\mathrm{NO}_{3}\right)_{2} \cdot 6 \mathrm{H}_{2} \mathrm{O}$ (11.5 g, $45.0 \mathrm{mmol}, 1.24$ equiv), $\mathrm{H}_{4} \operatorname{dobpdc}$ (9.90 g, $36.0 \mathrm{mmol}, 1.00$ equiv), $N, N$-dimethylformamide (DMF) $(90 \mathrm{~mL})$, and methanol $(110 \mathrm{~mL})$ were mixed together in a $350 \mathrm{~mL}$ glass heavy wall pressure vessel (Chemglass, CG-1880-42). The reaction mixture was sonicated for $15 \mathrm{~min}$ until all of the solids had dissolved, and was then sparged with $\mathrm{N}_{2}$ for $1 \mathrm{~h}$. The reaction vessel was sealed and heated at $120{ }^{\circ} \mathrm{C}$ with stirring for $21 \mathrm{~h}$. This resulted in the precipitation of a white solid from solution. The solid was collected via vacuum filtration and quickly returned to the reaction vessel along with fresh DMF $(250 \mathrm{~mL})$. The reaction vessel was then heated to $60{ }^{\circ} \mathrm{C}$ for $3 \mathrm{~h}$ with stirring. Following this, the solid was again collected via vacuum filtration and returned to the reaction vessel with fresh DMF $\left(250 \mathrm{~mL}\right.$ ) and again heated to $60{ }^{\circ} \mathrm{C}$ for $3 \mathrm{~h}$ with stirring. This washing process with DMF was repeated a total of three times, after which the solid was washed three more times in methanol $(250 \mathrm{~mL})$ at $60{ }^{\circ} \mathrm{C}$ to yield the desired product, $\mathrm{Mg}_{2}$ (dobpdc). A small portion of the product ( $\mathrm{ca} 0.1 \mathrm{~g}$ ) was collected via filtration and activated for characterisation by powder diffraction (Figure S10) by heating to $60{ }^{\circ} \mathrm{C}$ in $\mathrm{N}_{2}$ for $15 \mathrm{~h}$. The remaining $\mathrm{Mg}_{2}$ (dobpdc) was stored in methanol.

\section{Diamine-functionalised $\mathrm{Mg}_{2}$ (dobpdc) Synthesis}

Diamine-functionalised $\mathrm{Mg}_{2}$ (dobpdc) materials were synthesised according to a procedure previously reported in literature. ${ }^{1}$ Methanol-solvated $\mathrm{Mg}_{2}$ (dobpdc) was filtered and washed with toluene $(50 \mathrm{~mL})$. The filtered MOF $(c a 0.1-0.4 \mathrm{~g})$ was then added to a toluene $(4 \mathrm{~mL})$ and diamine $(1 \mathrm{~mL})$ solution and left to soak for at least $12 \mathrm{~h}$. The solid was then collected via vacuum filtration and washed with toluene $(50 \mathrm{~mL})$. e- $2, \mathrm{dmpn}$, ee-2, i-2 and ii-2, functionalised $\mathrm{Mg}_{2}$ (dobpdc) materials were activated by heating in an aluminium bead bath under $\mathrm{N}_{2}$ to $125{ }^{\circ} \mathrm{C}$ for $1 \mathrm{~h}, 150{ }^{\circ} \mathrm{C}$ for $1 \mathrm{~h}, 125^{\circ} \mathrm{C}$ for $1 \mathrm{~h}, 130^{\circ} \mathrm{C}$ for $1 \mathrm{~h}$, and for $130{ }^{\circ} \mathrm{C}$ for $1.5 \mathrm{~h}$, respectively. A portion (10-20 mg) was taken for powder X-ray diffraction analysis (Figure S10). To determine sample stoichiometries by ${ }^{1} \mathrm{H}$ NMR (Figure S9, Table S5), $5 \mathrm{mg}$ of the activated amine-functionalised MOFs was digested in a mixture of dimethyl sulfoxide $\left(\mathrm{DMSO}_{6}\right)(1 \mathrm{~mL})$ and two Pasteur pipette drops of deuterated hydrochloric acid (DCl) (35 wt $\%$ in $\mathrm{D}_{2} \mathrm{O}, \geq 99$ atom $\left.\% \mathrm{D}\right)$.

\section{$\mathrm{C}^{17} \mathrm{O}_{2}$ Dosing of Diamine-Appended MOFs}


The activated diamine-appended MOFs were packed into $4 \mathrm{~mm}$ NMR rotors inside a nitrogen-filled glovebag. Each sample was then evacuated for a minimum of $10 \mathrm{~min}$ in a home-built gas manifold, as described previously. ${ }^{2}{ }^{17} \mathrm{O}$-enriched $\mathrm{CO}_{2}$ gas $\left(20\right.$ at. $\left.\%{ }^{17} \mathrm{O}\right)$ was then used to dose the samples with gas at room temperature, before sealing the rotors inside the gas manifold with a mechanical plunger. (ee-2)- $\mathrm{Mg}_{2}$ (dobpdc) was dosed for $0.5 \mathrm{~h}$ with a final gas pressure of $896 \mathrm{mbar}$. The (dmpn)- $\mathrm{Mg}_{2}(\mathrm{dobpdc})$ sample for measurements at $20.0 \mathrm{~T}$ was dosed for $15 \mathrm{~h}$ with a final gas pressure of $1253 \mathrm{mbar}$, and the second independent (dmpn)- $\mathrm{Mg}_{2}$ (dobpdc) sample for measurements at $23.5 \mathrm{~T}$ was dosed with ${ }^{17} \mathrm{O}$-enriched $\mathrm{CO}_{2}$ for $15 \mathrm{~h}$ with a final gas pressure of 1113 mbar. (e-2)- $\mathrm{Mg}_{2}$ (dobpdc) was dosed for $1 \mathrm{~h}$, and the final gas pressure was 448 mbar. (i-2)- $\mathrm{Mg}_{2}$ (dobpdc) was dosed for $0.5 \mathrm{~h}$, and the final gas pressure was 1116 mbar. The (ii-2) $-\mathrm{Mg}_{2}$ (dobpdc) sample for measurements at $20.0 \mathrm{~T}$ was dosed for $0.75 \mathrm{~h}$ with a final gas pressure of $1015 \mathrm{mbar}$, and the second independent (ii-2)$\mathrm{Mg}_{2}$ (dobpdc) sample for measurements at 23.5 T was dosed with ${ }^{17} \mathrm{O}$-enriched $\mathrm{CO}_{2}$ for $0.5 \mathrm{~h}$ with a final gas pressure of 1039 mbar. For activated $\mathrm{Mg}_{2}$ (dobpdc) (i.e,. with no amines), activation was first carried out by heating in flowing nitrogen gas at $180{ }^{\circ} \mathrm{C}$ for $15 \mathrm{~h}$. This sample was then packed in an NMR rotor (as above) and dosed with gas for $0.5 \mathrm{~h}$, and the final gas pressure was 1075 mbar.

\section{NMR Spectroscopy}

${ }^{17} \mathrm{O}$ MAS and MQMAS experiments were performed using Bruker spectrometers equipped with a $20.0 \mathrm{~T}$ wide-bore and $23.5 \mathrm{~T}$ standard bore magnets, corresponding to a ${ }^{1} \mathrm{H}$ Larmor frequencies, $v_{0}$, of $850 \mathrm{MHz}$ and $1 \mathrm{GHz}$. For experiments at $20.0 \mathrm{~T}$, a Bruker Avance III spectrometer was used, alongside a Bruker $4 \mathrm{~mm}$ low- $\mathrm{\gamma}$ HX double resonance probe, and experiments were performed with an MAS frequency, $v_{\mathrm{R}}$, of $14 \mathrm{kHz} .{ }^{17} \mathrm{O}$ MAS spectra were acquired using a spin-echo pulse sequence with radiofrequency field strength, $v_{1}$, of $\sim 50 \mathrm{kHz}$ and a recycle delay of $0.05 \mathrm{~s}$. MQMAS experiments were acquired using a z-filter pulse sequence ${ }^{3-6}$ with triple-quantum excitation/conversion pulses with $v_{1} \approx 50 \mathrm{kHz}$ and a centraltransition selective $\pi / 2$ pulse at $v_{1} \approx 11 \mathrm{kHz}$. All MQMAS spectra are shown after shearing using the convention described in Ref. 35. For experiments at 23.5 T, a Bruker Avance NEO spectrometer equipped with a Bruker $3.2 \mathrm{~mm}$ HX double resonance probe was used with a MAS rate of $20 \mathrm{kHz} .{ }^{17} \mathrm{O}$ MAS spectra were acquired using a spin-echo pulse sequence, with $v_{1}=25 \mathrm{kHz}$, and with a recycle delay of $0.05 \mathrm{~s}$. Chemical shifts are given in ppm, and are referenced relative to liquid $\mathrm{H}_{2} \mathrm{O}$ at 0 ppm.

\section{DFT Calculations}

The candidate structures were first geometry optimised using CASTEP. ${ }^{7-19}$ This was done with i) plane-wave basis set with an $80 \mathrm{Ry}(1088 \mathrm{eV})$ cut-off energy, ii) the on-the-fly generated ultrasoft pseudopotential (C17), iii) a 1x1x3 k-point grid, iv) the Perdew-BurkeErnzerhol (PBE) functional with a G06 Van de Waals correction.

The NMR parameters were calculated using the same parameters and this gave values of $\delta_{\text {iso, }}$, anisotropy, asymmetry, $\mathrm{C}_{\mathrm{Q}}$ and $\eta_{\mathrm{Q}}$ which converged within $0.1 \mathrm{ppm}, 0.25 \mathrm{ppm}, 0.001,0.0$ 
$\mathrm{MHz}$ and 0.0 respectively for the investigated oxygen and carbon nuclei at the selected kpoint grid and cutoff energy.

For ${ }^{13} \mathrm{C}$ and ${ }^{17} \mathrm{O}$ NMR, the principal components of the chemical shielding tensor $\left(\sigma_{11}, \sigma_{22}\right.$ and $\sigma_{33}$ where $\sigma_{33} \geq \sigma_{22} \geq \sigma_{11}$ ) were obtained directly from the CASTEP calculations, in terms of $\sigma_{\mathrm{xx}}, \sigma_{\mathrm{yy}}$ and $\sigma_{\mathrm{zz}}$ where $\left|\sigma_{\mathrm{zz}}-\sigma_{\text {iso }}\right| \geq\left|\sigma_{\mathrm{xx}}-\sigma_{\text {iso }}\right| \geq\left|\sigma_{\mathrm{yy}}-\sigma_{\text {iso }}\right|$. The principal components of the chemical shielding tensor were converted to chemical shift principal components using $\delta$ $=-\left(\sigma_{\text {calc }}-\sigma_{\text {ref }}\right)$ where the reference values for ${ }^{13} \mathrm{C}$ and ${ }^{17} \mathrm{O}$ were 171.2 and $249.8 \mathrm{ppm}$, respectively. These values were obtained from CASTEP calculations on cocaine $\left({ }^{13} \mathrm{C}\right)^{20}$ and the amino acids tyrosine and valine $\left({ }^{17} \mathrm{O}\right),{ }^{21}$ and correlation of the calculated values with the experimental values with a linear fit with a fixed gradient of -1 .

\section{Methods References}

(1) Siegelman, R. L.; McDonald, T. M.; Gonzalez, M. I.; Martell, J. D.; Milner, P. J.; Mason, J. A.; Berger, A. H.; Bhown, A. S.; Long, J. R. Controlling Cooperative CO2 Adsorption in DiamineAppended Mg2(Dobpdc) Metal-Organic Frameworks. Journal of the American Chemical Society 2017, 139 (30). https://doi.org/10.1021/jacs.7b05858.

(2) Forse, A. C.; Milner, P. J.; Lee, J. H.; Redfearn, H. N.; Oktawiec, J.; Siegelman, R. L.; Martell, J. D.; Dinakar, B.; Porter-Zasada, L. B.; Gonzalez, M. I.; Neaton, J. B.; Long, J. R.; Reimer, J. A. Elucidating CO 2 Chemisorption in Diamine-Appended Metal-Organic Frameworks. Journal of the American Chemical Society 2018, 140 (51). https://doi.org/10.1021/jacs.8b10203.

(3) Pike, K. J.; Malde, R. P.; Ashbrook, S. E.; McManus, J.; Wimperis, S. Multiple-Quantum MAS NMR of Quadrupolar Nuclei. Do Five-, Seven- and Nine-Quantum Experiments Yield Higher Resolution than the Three-Quantum Experiment? Solid State Nuclear Magnetic Resonance 2000, 16 (3). https://doi.org/10.1016/S0926-2040(00)00081-3.

(4) Ashbrook, S. E.; Sneddon, S. New Methods and Applications in Solid-State NMR Spectroscopy of Quadrupolar Nuclei. Journal of the American Chemical Society 2014, 136 (44). https://doi.org/10.1021/ja504734p.

(5) Amoureux, J. P.; Fernandez, C.; Steuernagel, S. Z Filtering in MQMAS NMR. Journal of Magnetic Resonance - Series A. 1996. https://doi.org/10.1006/jmra.1996.0221.

(6) Frydman, L.; Harwood, J. S. Isotropic Spectra of Half-Integer Quadrupolar Spins from Bidimensional Magic-Angle Spinning NMR. Journal of the American Chemical Society 1995, 117 (19). https://doi.org/10.1021/ja00124a023.

(7) Hohenberg, P.; Kohn, W. Inhomogeneous Electron Gas. Physical Review 1964, 136 (3B). https://doi.org/10.1103/PhysRev.136.B864.

(8) Kohn, W.; Sham, L. J. Self-Consistent Equations Including Exchange and Correlation Effects. Physical Review 1965, 140 (4A). https://doi.org/10.1103/PhysRev.140.A1133.

(9) Payne, M. C.; Teter, M. P.; Allan, D. C.; Arias, T. A.; Joannopoulos, J. D. Iterative Minimization Techniques for Ab Initio Total-Energy Calculations: Molecular Dynamics and Conjugate Gradients. Reviews of Modern Physics 1992, 64 (4). https://doi.org/10.1103/RevModPhys.64.1045. 
(10) Clark, S. J.; Segall, M. D.; Pickard, C. J.; Hasnip, P. J.; Probert, M. I. J.; Refson, K.; Payne, M. C. First Principles Methods Using CASTEP. Zeitschrift fur Kristallographie 2005, 220 (5-6). https://doi.org/10.1524/zkri.220.5.567.65075.

(11) Pickard, C. J.; Mauri, F. All-Electron Magnetic Response with Pseudopotentials: NMR Chemical Shifts. Physical Review B - Condensed Matter and Materials Physics 2001, 63 (24). https://doi.org/10.1103/physrevb.63.245101.

(12) Yates, J. R.; Pickard, C. J.; Mauri, F. Calculation of NMR Chemical Shifts for Extended Systems Using Ultrasoft Pseudopotentials. Physical Review B - Condensed Matter and Materials Physics 2007, 76 (2). https://doi.org/10.1103/PhysRevB.76.024401.

(13) Profeta, M.; Mauri, F.; Pickard, C. J. Accurate First Principles Prediction of 170 NMR Parameters in SiO2: Assignment of the Zeolite Ferrierite Spectrum. Journal of the American Chemical Society 2003, 125 (2). https://doi.org/10.1021/ja027124r.

(14) Bonhomme, C.; Gervais, C.; Babonneau, F.; Coelho, C.; Pourpoint, F.; Azaïs, T.; Ashbrook, S. E.; Griffin, J. M.; Yates, J. R.; Mauri, F.; Pickard, C. J. First-Principles Calculation of NMR Parameters Using the Gauge Including Projector Augmented Wave Method: A Chemists Point of View. Chemical Reviews. 2012. https://doi.org/10.1021/cr300108a.

(15) Grimme, S. Semiempirical GGA-Type Density Functional Constructed with a Long-Range Dispersion Correction. Journal of Computational Chemistry 2006, 27 (15). https://doi.org/10.1002/jcc.20495.

(16) McNellis, E. R.; Meyer, J.; Reuter, K. Azobenzene at Coinage Metal Surfaces: Role of Dispersive van Der Waals Interactions. Physical Review B - Condensed Matter and Materials Physics 2009, 80 (20). https://doi.org/10.1103/PhysRevB.80.205414.

(17) Pfrommer, B. G.; Côté, M.; Louie, S. G.; Cohen, M. L. Relaxation of Crystals with the Quasi-Newton Method. Journal of Computational Physics 1997, 131 (1). https://doi.org/10.1006/jcph.1996.5612.

(18) Francis, G. P.; Payne, M. C. Finite Basis Set Corrections to Total Energy Pseudopotential Calculations. Journal of Physics: Condensed Matter 1990, 2 (19). https://doi.org/10.1088/0953$8984 / 2 / 19 / 007$.

(19) Monkhorst, H. J.; Pack, J. D. Special Points for Brillouin-Zone Integrations. Physical Review B 1976, 13 (12). https://doi.org/10.1103/PhysRevB.13.5188.

(20) Baias, M.; Widdifield, C. M.; Dumez, J. N.; Thompson, H. P. G.; Cooper, T. G.; Salager, E.; Bassil, S.; Stein, R. S.; Lesage, A.; Day, G. M.; Emsley, L. Powder Crystallography of Pharmaceutical Materials by Combined Crystal Structure Prediction and Solid-State 1H NMR Spectroscopy. Physical Chemistry Chemical Physics 2013, 15 (21). https://doi.org/10.1039/c3cp41095a.

(21) Pike, K. J.; Lemaitre, V.; Kukol, A.; Anupõld, T.; Samoson, A.; Howes, A. P.; Watts, A.; Smith, M. E.; Dupree, R. 170 Solid-State NMR of Amino Acids. The Journal of Physical Chemistry B 2004, 108.

\section{Data availability}

The PXRD, NMR and DFT structures are available in the Cambridge Research Repository, Apollo, with the identifier .... 


\section{Acknowledgements}

This work was also supported by a UKRI Future Leaders Fellowship to A.C.F. (MR/T043024/1). We thank the Yusuf Hamied Department of Chemistry at Cambridge for the award of a BP Next Generation Fellowship to A.C.F., and the NanoDTC ESPSRC Grant EP/S022953/1 for support to M.I.M.S. and A.C.F. The UK High-Field Solid-State NMR Facility used in this research was funded by EPSRC and BBSRC (EP/T015063/1), as well as the University of Warwick including via part funding through Birmingham Science City Advanced Materials Projects 1 and 2 supported by Advantage West Midlands (AWM) and the European Regional Development Fund (ERDF), as well as, for the $1 \mathrm{GHz}$ instrument, EP/R029946/1. This work was performed using resources provided by the Cambridge Service for Data Driven Discovery (CSD3) operated by the University of Cambridge Research Computing Service (www.csd3.cam.ac.uk), provided by Dell EMC and Intel using Tier-2 funding from the Engineering and Physical Sciences Research Council (capital grant EP/P020259/1), and DiRAC funding from the Science and Technology Facilities Council (www.dirac.ac.uk). J.-H.L.'s work and computational resources were supported by the KIST Institutional Program (Project No. 2E31201) and KISTI Supercomputing Centre (Project No. KSC-2020-CRE-0189). We thank Halle N. Redfearn for carrying out initial ${ }^{13} \mathrm{C}$ NMR measurements on ii-2- $\mathrm{Mg}_{2}($ dobpdc). We thank Prof. Jeffrey Reimer, Prof. Jeffrey Long and Prof. Phillip Milner for helpful discussions on amine-functionalised MOFs.

\section{Contributions}

A.B., Z.L., J.-H.L, C.J.P. and A.C.F. carried out DFT calculations and analysis. M.I.M.S., A.C.F. and S.M.P. carried out MOF synthesis and characterisation. S.M.P. carried out solidstate NMR measurements, and S.M.P, A.B., and A.C.F. analysed the NMR data. A.B. wrote the manuscript with contributions from all the coauthors. A.C.F. designed the study.

\section{Corresponding Author}

Correspondence to Alexander C. Forse. 


\section{Extended data}

Table S1. - Overview of the amine-functionalised frameworks investigated in the DFT calculations together with the studied $\mathrm{CO}_{2}$ adsorption classifications. Unless alternate metals are listed, it is assumed that the $\mathrm{Mg}$ framework, i.e., $\mathrm{Mg}_{2}$ (dobpdc), is functionalised with the amine shown. (chain = ammonium carbamate chain, pairs = carbamic acid pairs, mixed = mixed ammonium carbamate - carbamic acid) Unsymmetrical amines are assumed to form a metal-nitrogen bond with the less sterically hindered amine, and also to react with $\mathrm{CO}_{2}$ at that same amine. Two $(\mathrm{R}, \mathrm{R})$-dach compounds are listed as this chiral diamine interacts with the chiral $\mathrm{M}_{2}$ (dobpdc) framework to form two distinct enantiomers. ${ }^{3}$ One tetraaminefunctionalised framework was considered, known as 3-4-3- $\mathrm{Mg}_{2}(\mathrm{dobpdc}){ }^{1}$

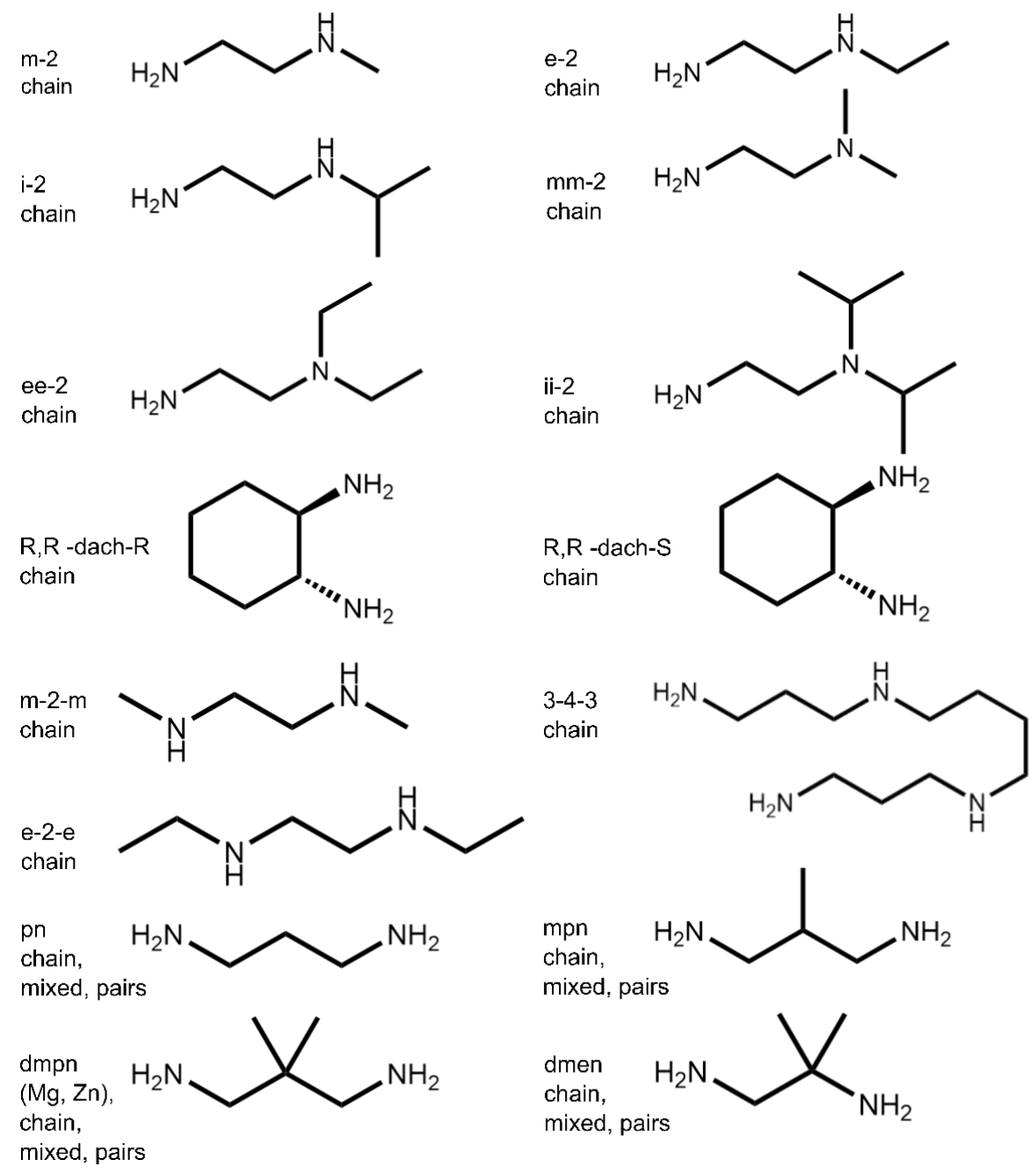


(a)
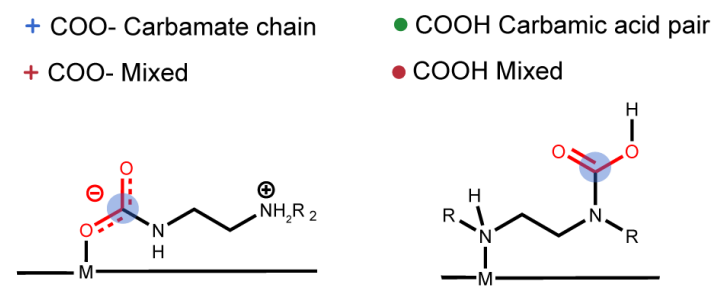

(b)
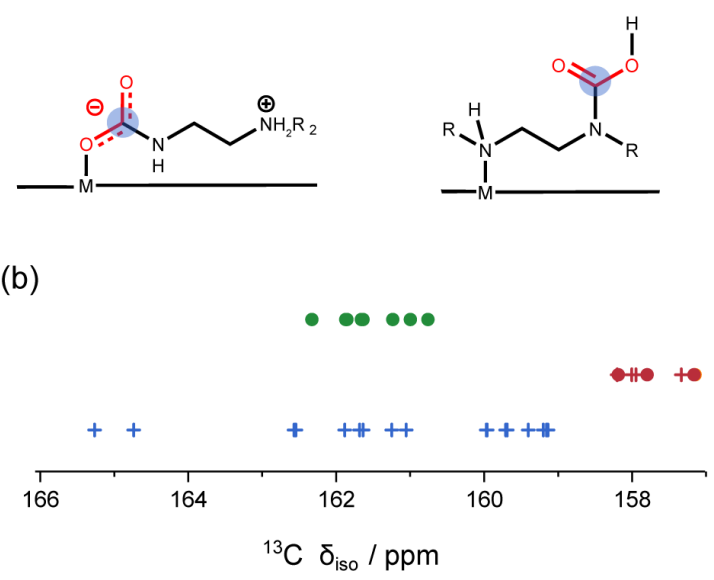

(c)

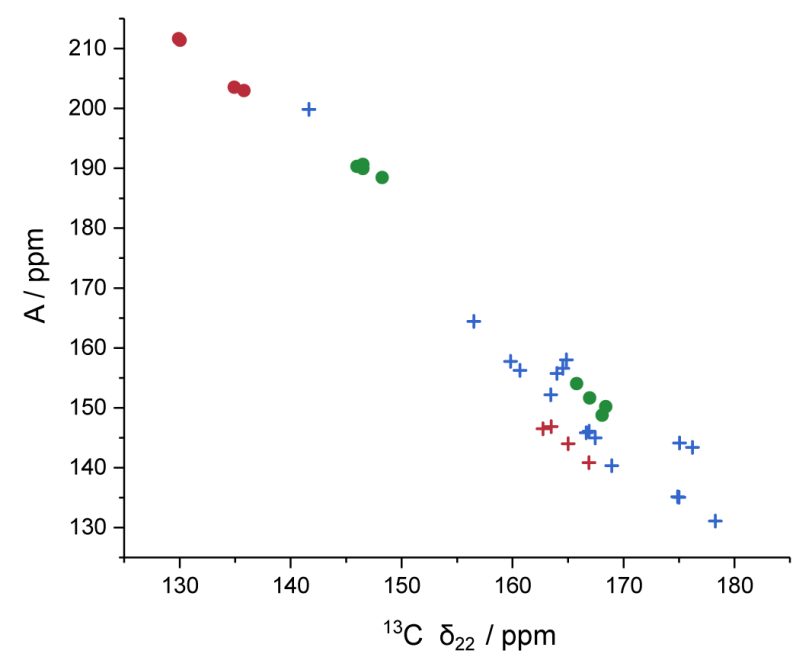

Figure S1. - Differentiation of adsorption modes based on ${ }^{13} \mathbf{C}$ NMR. a) Illustrations showing the different carbon environments present in the different $\mathrm{CO}_{2}$ adsorption structures. b) An overview of the DFT-calculated ${ }^{13} \mathrm{C}$ isotropic chemical shifts for the different classifications showing no clear differentiation between ammonium carbamate chains and carbamic acids. The chemical shift anisotropy of the DFT-calculated ${ }^{13} \mathrm{C}$ NMR shift was also investigated. A plot of $\mathrm{A}=\left(\delta_{11}+\delta_{33}-\delta_{22}\right)$ vs $\delta_{22}$ has been shown to differentiate protonated and deprotonated forms of $\mathrm{CO}_{2}$ adsorbed in amine functionalised silica materials. ${ }^{4}$ For our materials, less of a clear differentiation is seen (Figure S1c). 
Table S2a. - The ${ }^{13}$ C NMR parameters obtained from DFT calculations for ammonium carbamate chain structures.

*structure at full $\mathrm{CO}_{2}$ capacity ${ }^{1}$

**structure at half $\mathrm{CO}_{2}$ capacity ${ }^{1}$

$* * *$ This structure formed a chain structure with the inserted $\mathrm{CO}_{2}$ being protonated.

\begin{tabular}{|c|c|c|c|c|c|c|c|c|c|}
\hline Compound & $\begin{array}{l}\delta_{\text {iso }} \\
(\mathrm{ppm})\end{array}$ & $\begin{array}{l}\delta_{11} \\
(\mathrm{ppm})\end{array}$ & $\begin{array}{l}\delta_{22} \\
(\mathrm{ppm})\end{array}$ & $\begin{array}{l}\delta_{33} \\
(\mathrm{ppm})\end{array}$ & Compound & $\begin{array}{l}\delta_{\text {iso }} \\
(\mathrm{ppm})\end{array}$ & $\begin{array}{l}\delta_{11} \\
(\mathrm{ppm})\end{array}$ & $\begin{array}{l}\delta_{22} \\
(\mathrm{ppm})\end{array}$ & $\begin{array}{l}\delta_{33} \\
(\mathrm{ppm})\end{array}$ \\
\hline $\begin{array}{l}\mathrm{e}-2- \\
\mathrm{Mg}_{2}(\mathrm{dobpdc})\end{array}$ & 159.97 & 204.68 & 166.90 & 108.33 & $\begin{array}{l}\mathrm{m}-2- \\
\mathrm{Mg}_{2}(\mathrm{dobpdc})\end{array}$ & 159.40 & 202.84 & 168.94 & 106.43 \\
\hline $\begin{array}{l}\text { ee-2- } \\
\mathrm{Mg}_{2}(\text { dobpdc })\end{array}$ & 159.96 & 206.80 & 167.45 & 105.62 & $\begin{array}{l}\mathrm{i}-2- \\
\mathrm{Mg}_{2}(\text { dobpdc })\end{array}$ & 161.05 & 231.63 & 141.66 & 109.88 \\
\hline $\begin{array}{l}\mathrm{mm}-2- \\
\mathrm{Mg}_{2} \text { (dobpdc) }\end{array}$ & 159.71 & 206.76 & 166.64 & 105.73 & $\begin{array}{l}\mathrm{m} 2 \mathrm{~m}- \\
\mathrm{Mg}_{2}(\mathrm{dobpdc})\end{array}$ & 162.57 & 212.85 & 164.85 & 110.01 \\
\hline $\begin{array}{l}\text { dmen- } \\
\mathrm{Mg}_{2}(\text { dobpdc) }\end{array}$ & 161.88 & 214.75 & 164.53 & 106.37 & $\begin{array}{l}\text { pn- } \\
\mathrm{Mg}_{2}(\text { dobpdc })\end{array}$ & 165.27 & 215.03 & 176.21 & 104.56 \\
\hline $\begin{array}{l}\text { mpn- } \\
\mathrm{Mg}_{2}(\text { dobpdc })\end{array}$ & 164.74 & 214.58 & 175.04 & 104.59 & $\begin{array}{l}\text { dmpn-- } \\
\mathrm{Mg}_{2}(\text { dobpdc })\end{array}$ & 159.20 & 208.87 & 160.67 & 108.06 \\
\hline $\begin{array}{l}\text { dmpn- } \\
\mathrm{Zn}_{2} \text { (dobpdc) }\end{array}$ & 159.14 & 208.16 & 159.82 & 109.43 & $\begin{array}{l}\text { (R,R)dach-R- } \\
\mathrm{Mg}_{2} \text { (dobpdc) }\end{array}$ & 159.16 & 210.95 & 156.51 & 110.01 \\
\hline $\begin{array}{l}\text { (R,R)dach-S- } \\
\mathrm{Mg}_{2} \text { (dobpdc) }\end{array}$ & 159.69 & 207.18 & 163.44 & 108.44 & $\begin{array}{l}\text { e-2-e- } \\
\mathrm{Mg}_{2}(\text { dobpdc })\end{array}$ & 161.25 & 209.05 & 164.00 & 110.71 \\
\hline $\begin{array}{l}343- \\
\mathrm{Mg}_{2}(\text { dobpdc })^{*}\end{array}$ & 161.68 & 203.62 & 174.99 & 106.44 & $\begin{array}{l}343- \\
\mathrm{Mg}_{2}(\text { dobpdc })^{* *}\end{array}$ & 162.54 & 204.19 & 178.27 & 105.17 \\
\hline $\mathrm{e} 2 * * *$ & 159.41 & 215.30 & 158.69 & 104.24 & & & & & \\
\hline
\end{tabular}


Table S2b. - The ${ }^{13} \mathrm{C}$ parameters obtained from DFT calculations on mixed adsorption structures. For each structure there are two ${ }^{13} \mathrm{C}$ environments.

*This structure formed an alternative mixed structure consisting of one chain of ammonium carbamates, and one chain of carbamic acids.

\begin{tabular}{|c|c|c|c|c|c|}
\hline Compound & Environment & $\begin{array}{l}\delta_{\text {iso }} \\
(\mathrm{ppm})\end{array}$ & $\begin{array}{l}\delta_{11} \\
(\mathrm{ppm})\end{array}$ & $\begin{array}{l}\delta_{22} \\
(\mathrm{ppm})\end{array}$ & $\begin{array}{l}\delta_{33} \\
(\mathrm{ppm})\end{array}$ \\
\hline \multirow[t]{2}{*}{ pn- $\mathrm{Mg}_{2}(\mathrm{dobpdc})$} & $\mathrm{M}-\mathrm{OCO}$ & 157.95 & 203.25 & 163.49 & 107.10 \\
\hline & $\mathrm{COOH}$ & 157.16 & 231.31 & 130.05 & 110.13 \\
\hline \multirow{2}{*}{$\begin{array}{l}\mathrm{mpn}- \\
\mathrm{Mg}_{2}(\text { dobpdc })\end{array}$} & $\mathrm{M}-\mathrm{OCO}$ & 157.33 & 202.51 & 162.75 & 106.74 \\
\hline & $\mathrm{COOH}$ & 157.15 & 231.83 & 129.90 & 109.71 \\
\hline \multirow{2}{*}{$\begin{array}{l}\text { dmpn- } \\
\mathrm{Mg}_{2} \text { (dobpdc) }\end{array}$} & $\mathrm{M}-\mathrm{OCO}$ & 158.20 & 201.08 & 166.88 & 106.65 \\
\hline & $\mathrm{COOH}$ & 157.80 & 232.72 & 134.92 & 105.75 \\
\hline \multirow{2}{*}{$\begin{array}{l}\text { dmpn- } \\
\mathrm{Zn}_{2} \text { (dobpdc) }\end{array}$} & $\mathrm{M}-\mathrm{OCO}$ & 158.01 & 201.17 & 165.01 & 107.84 \\
\hline & $\mathrm{COOH}$ & 158.19 & 231.23 & 135.79 & 107.53 \\
\hline \multirow{2}{*}{$\begin{array}{l}\text { ii2- } \\
\mathrm{Mg}_{2}(\text { dobpdc })^{*}\end{array}$} & $\mathrm{M}-\mathrm{OCO}$ & 162.85 & 214.15 & 166.15 & 108.24 \\
\hline & $\mathrm{M}-\mathrm{OCOH}$ & 158.92 & 215.67 & 157.03 & 104.07 \\
\hline
\end{tabular}


Table S2c. - The ${ }^{13} \mathrm{C}$ parameters obtained from DFT calculations on carbamic acid pair structures. The carbamic acid pairs show two different carbon environments. This is due to them being unsymmetric with respect to the organic linker backbone. In this table $\mathrm{COOH}^{\mathrm{a}}$ refers to the part of the pair with the $\mathrm{C}=\mathrm{O}$ bond pointing towards the backbone. The $\mathrm{COOH}^{\mathrm{b}}$ structure refers to the part of the pair with the $\mathrm{C}-\mathrm{OH}$ pointing towards the backbone.

\begin{tabular}{|c|c|c|c|c|c|}
\hline Compound & Environment & $\begin{array}{l}\delta_{\text {iso }} \\
(\mathrm{ppm})\end{array}$ & $\begin{array}{l}\delta_{11} \\
(\mathrm{ppm})\end{array}$ & $\begin{array}{l}\delta_{22} \\
(\mathrm{ppm})\end{array}$ & $\begin{array}{l}\delta_{33} \\
(\mathrm{ppm})\end{array}$ \\
\hline pn- $\mathrm{Mg}_{2}($ dobpdc $)$ & $\mathrm{COOH}^{\mathrm{a}}$ & 161.85 & 214.58 & 166.95 & 104.03 \\
\hline pn- $\mathrm{Mg}_{2}(\mathrm{dobpdc})$ & $\mathrm{COOH}^{\mathrm{b}}$ & 161.00 & 228.83 & 146.52 & 107.63 \\
\hline $\begin{array}{l}\text { mpn- } \\
\mathrm{Mg}_{2}(\text { dobpdc })\end{array}$ & $\mathrm{COOH}^{\mathrm{a}}$ & 161.64 & 213.46 & 168.07 & 103.37 \\
\hline $\begin{array}{l}\text { mpn- } \\
\mathrm{Mg}_{2}(\text { dobpdc })\end{array}$ & $\mathrm{COOH}^{\mathrm{b}}$ & 160.76 & 228.91 & 145.98 & 107.39 \\
\hline $\begin{array}{l}\text { dmpn- } \\
\mathrm{Mg}_{2}(\text { dobpdc) }\end{array}$ & $\mathrm{COOH}^{\mathrm{a}}$ & 161.87 & 216.68 & 165.78 & 103.15 \\
\hline $\begin{array}{l}\text { dmpn- } \\
\operatorname{Mg}_{2}(\text { dobpdc) }\end{array}$ & $\mathrm{COOH}^{\mathrm{b}}$ & 161.23 & 230.39 & 146.52 & 106.79 \\
\hline $\begin{array}{l}\text { dmpn- } \\
\mathrm{Zn}_{2} \text { (dobpdc) }\end{array}$ & $\mathrm{COOH}^{\mathrm{a}}$ & 162.33 & 215.30 & 168.40 & 103.29 \\
\hline $\begin{array}{l}\text { dmpn- } \\
\mathrm{Zn}_{2}(\text { dobpdc })\end{array}$ & $\mathrm{COOH}^{\mathrm{b}}$ & 161.66 & 229.99 & 148.26 & 106.73 \\
\hline
\end{tabular}


Table S3a. - The ${ }^{17}$ O NMR parameters obtained from DFT calculations on ammonium carbamate chain structures.

*structure at full $\mathrm{CO}_{2}$ capacity ${ }^{1}$

$* *$ structure at half $\mathrm{CO}_{2}$ capacity ${ }^{1}$

***This structure formed a chain structure with the inserted $\mathrm{CO}_{2}$ being protonated.

\begin{tabular}{|c|c|c|c|c|c|c|c|c|c|}
\hline Compound & Site & $\begin{array}{l}\delta_{\text {iso }} \\
(\mathrm{ppm})\end{array}$ & $\begin{array}{l}\mathrm{C}_{\mathrm{Q}} \\
(\mathrm{MHz})\end{array}$ & $\eta_{\mathrm{Q}}$ & Compound & Site & $\begin{array}{l}\delta_{\text {iso }} \\
(\mathrm{ppm})\end{array}$ & $\begin{array}{l}\mathrm{C}_{\mathrm{Q}} \\
(\mathrm{MHz})\end{array}$ & $\eta_{\mathrm{Q}}$ \\
\hline $\begin{array}{l}\text { e-2- } \\
\mathrm{Mg}_{2}(\text { dobpdc })\end{array}$ & $\begin{array}{l}\mathrm{M}-\mathrm{OCO} \\
\mathrm{M}-\mathrm{OCO}\end{array}$ & $\begin{array}{l}174.09 \\
175.05\end{array}$ & $\begin{array}{l}-7.30 \\
-7.25\end{array}$ & $\begin{array}{l}0.91 \\
0.68\end{array}$ & $\begin{array}{l}\mathrm{m}-2- \\
\mathrm{Mg}_{2}(\text { dobpdc })\end{array}$ & $\begin{array}{l}\text { M-OCO } \\
\text { M-OCO }\end{array}$ & $\begin{array}{l}176.03 \\
171.00\end{array}$ & $\begin{array}{l}-7.31 \\
-7.32\end{array}$ & $\begin{array}{l}0.96 \\
0.67\end{array}$ \\
\hline $\begin{array}{l}\text { ee-2- } \\
\mathrm{Mg}_{2}(\text { dobpdc })\end{array}$ & $\begin{array}{l}\text { M-OCO } \\
\text { M-OCO }\end{array}$ & $\begin{array}{l}169.10 \\
185.47\end{array}$ & $\begin{array}{l}-7.35 \\
-6.97\end{array}$ & $\begin{array}{l}0.95 \\
0.72\end{array}$ & $\begin{array}{l}\mathrm{i}-2- \\
\mathrm{Mg}_{2}(\text { dobpdc })\end{array}$ & $\begin{array}{l}\mathrm{M}-\mathrm{OCO} \\
\mathrm{M}-\mathrm{OCO}\end{array}$ & $\begin{array}{l}168.78 \\
224.16\end{array}$ & $\begin{array}{l}-7.56 \\
7.94\end{array}$ & $\begin{array}{l}0.43 \\
0.50\end{array}$ \\
\hline $\begin{array}{l}\mathrm{mm}-2- \\
\mathrm{Mg}_{2}(\text { dobpdc })\end{array}$ & $\begin{array}{l}\text { M-OCO } \\
\text { M-OCO }\end{array}$ & $\begin{array}{l}177.14 \\
164.95\end{array}$ & $\begin{array}{l}-7.37 \\
-7.15\end{array}$ & $\begin{array}{l}0.93 \\
0.66\end{array}$ & $\begin{array}{l}\mathrm{m}-2-\mathrm{m}- \\
\mathrm{Mg}_{2}(\text { dobpdc })\end{array}$ & $\begin{array}{l}\text { M-OCO } \\
\text { M-OCO }\end{array}$ & $\begin{array}{l}151.18 \\
194.47\end{array}$ & $\begin{array}{l}-7.64 \\
-6.92\end{array}$ & $\begin{array}{l}0.97 \\
0.88\end{array}$ \\
\hline $\begin{array}{l}\text { dmen- } \\
\operatorname{Mg}_{2}(\text { dobpdc })\end{array}$ & $\begin{array}{l}\mathrm{M-OCO} \\
\text { M-OCO }\end{array}$ & $\begin{array}{l}160.17 \\
202.07\end{array}$ & $\begin{array}{l}7.68 \\
6.48\end{array}$ & $\begin{array}{l}0.96 \\
0.91\end{array}$ & $\begin{array}{l}\text { pn- } \\
\mathrm{Mg}_{2}(\text { dobpdc })\end{array}$ & $\begin{array}{l}\text { M-OCO } \\
\text { M-OCO }\end{array}$ & $\begin{array}{l}158.73 \\
195.46\end{array}$ & $\begin{array}{l}7.75 \\
6.74\end{array}$ & $\begin{array}{l}0.73 \\
0.84\end{array}$ \\
\hline $\begin{array}{l}\text { mpn- } \\
\operatorname{Mg}_{2}(\text { dobpdc })\end{array}$ & $\begin{array}{l}\text { M-OCO } \\
\text { M-OCO }\end{array}$ & $\begin{array}{l}161.76 \\
199.02\end{array}$ & $\begin{array}{l}7.64 \\
6.73\end{array}$ & $\begin{array}{l}0.88 \\
0.91\end{array}$ & $\begin{array}{l}\text { dmpn- } \\
\mathrm{Mg}_{2}(\text { dobpdc })\end{array}$ & $\begin{array}{l}\mathrm{M}-\mathrm{OCO} \\
\mathrm{M}-\mathrm{OCO}\end{array}$ & $\begin{array}{l}172.59 \\
192.79\end{array}$ & $\begin{array}{l}-7.63 \\
-6.93\end{array}$ & $\begin{array}{l}0.94 \\
0.98\end{array}$ \\
\hline $\begin{array}{l}\text { dmpn- } \\
\mathrm{Zn}_{2}(\text { dobpdc })\end{array}$ & $\begin{array}{l}\text { M-OCO } \\
\text { M-OCO }\end{array}$ & $\begin{array}{l}170.73 \\
192.46\end{array}$ & $\begin{array}{l}-8.28 \\
-6.90\end{array}$ & $\begin{array}{l}0.91 \\
0.95\end{array}$ & $\begin{array}{l}\text { e2e- } \\
\mathrm{Mg}_{2}(\text { dobpdc })\end{array}$ & $\begin{array}{l}\text { M-OCO } \\
\text { M-OCO }\end{array}$ & $\begin{array}{l}161.16 \\
200.56\end{array}$ & $\begin{array}{l}-7.61 \\
-7.04\end{array}$ & $\begin{array}{l}0.93 \\
0.98\end{array}$ \\
\hline $\begin{array}{l}343- \\
\mathrm{Mg}_{2}(\text { dobpdc)* }\end{array}$ & $\begin{array}{l}\text { M-OCO } \\
\text { M-OCO }\end{array}$ & $\begin{array}{l}164.73 \\
183.41\end{array}$ & $\begin{array}{l}7.52 \\
-7.11\end{array}$ & $\begin{array}{l}0.84 \\
0.72\end{array}$ & $\begin{array}{l}343- \\
\mathrm{Mg}_{2}(\text { dobpdc }) \\
* *\end{array}$ & $\begin{array}{l}\text { M-OCO } \\
\text { M-OCO }\end{array}$ & $\begin{array}{l}170.73 \\
188.99\end{array}$ & $\begin{array}{l}-7.47 \\
-7.14\end{array}$ & $\begin{array}{l}0.87 \\
0.85\end{array}$ \\
\hline $\begin{array}{l}\mathrm{e} 2- \\
\mathrm{Mg}_{2}(\mathrm{dobpdc}) * * *\end{array}$ & $\begin{array}{l}\text { M-OCOH } \\
\text { M-OCOH }\end{array}$ & $\begin{array}{l}175.74 \\
135.75\end{array}$ & $\begin{array}{l}7.26 \\
-7.94\end{array}$ & $\begin{array}{l}0.98 \\
0.37\end{array}$ & & & & & \\
\hline
\end{tabular}


Table S3b. - The ${ }^{17}$ O NMR parameters obtained from DFT calculations on mixed adsorption structures.

*This structure formed an alternative mixed structure consisting of one chain of ammonium carbamates, and one chain of carbamic acids.

\begin{tabular}{|c|c|c|c|c|c|c|c|c|c|}
\hline Compound & $\begin{array}{l}\text { Environm } \\
\text { ent }\end{array}$ & $\begin{array}{l}\delta_{\text {iso }} \\
(\mathrm{ppm})\end{array}$ & $\begin{array}{l}\mathrm{C}_{\mathrm{Q}} \\
(\mathrm{MHz})\end{array}$ & $\eta_{\mathrm{Q}}$ & Compound & $\begin{array}{l}\text { Environm } \\
\text { ent }\end{array}$ & $\begin{array}{l}\delta_{\text {iso }} \\
\text { (ppm) }\end{array}$ & $\begin{array}{l}\mathrm{C}_{\mathrm{Q}} \\
(\mathrm{MHz})\end{array}$ & $\eta_{\mathrm{Q}}$ \\
\hline $\begin{array}{l}\text { pn- } \\
\mathrm{Mg}_{2}(\text { dobpdc })\end{array}$ & $\begin{array}{l}\mathrm{M}-\mathrm{OCO} \\
\mathrm{M}-\mathrm{OCO} \\
\mathrm{COOH} \\
\mathrm{COOH}\end{array}$ & $\begin{array}{l}168.20 \\
181.21 \\
220.59 \\
117.34\end{array}$ & $\begin{array}{l}-7.57 \\
-7.23 \\
7.64 \\
-8.21\end{array}$ & $\begin{array}{l}0.98 \\
0.97 \\
0.59 \\
0.46\end{array}$ & $\begin{array}{l}\text { mpn- } \\
\mathrm{Mg}_{2}(\text { dobpdc })\end{array}$ & $\begin{array}{l}\text { M-OCO } \\
\text { M-OCO } \\
\mathrm{COOH} \\
\mathrm{COOH}\end{array}$ & $\begin{array}{l}168.15 \\
182.32 \\
220.90 \\
118.11\end{array}$ & $\begin{array}{l}-7.54 \\
-7.24 \\
7.68 \\
-8.19\end{array}$ & $\begin{array}{l}0.98 \\
0.96 \\
0.58 \\
0.46\end{array}$ \\
\hline $\begin{array}{l}\text { dmpn- } \\
\operatorname{Mg}_{2}(\text { dobpdc })\end{array}$ & $\begin{array}{l}\text { M-OCO } \\
\text { M-OCO } \\
\mathrm{COOH} \\
\mathrm{COOH}\end{array}$ & $\begin{array}{r}165.56 \\
182.68 \\
229.71 \\
130.65\end{array}$ & $\begin{array}{l}-7.56 \\
-7.23 \\
7.87 \\
-8.18\end{array}$ & $\begin{array}{l}0.96 \\
0.87 \\
0.55 \\
0.39\end{array}$ & $\begin{array}{l}\text { dmpn- } \\
\mathrm{Zn}_{2}(\text { dobpdc })\end{array}$ & $\begin{array}{l}\text { M-OCO } \\
\text { M-OCO } \\
\mathrm{COOH} \\
\mathrm{COOH}\end{array}$ & $\begin{array}{l}164.87 \\
185.12 \\
222.77 \\
125.23\end{array}$ & $\begin{array}{l}-8.23 \\
-7.15 \\
7.78 \\
-8.22\end{array}$ & $\begin{array}{l}0.92 \\
0.89 \\
0.59 \\
0.42\end{array}$ \\
\hline $\begin{array}{l}\mathrm{ii}-2- \\
\mathrm{Mg}_{2}(\text { dobpdc })^{*}\end{array}$ & $\begin{array}{l}\text { M-OCO } \\
\text { M-OCO } \\
\mathrm{COOH} \\
\mathrm{COOH}\end{array}$ & $\begin{array}{l}175.77 \\
203.04 \\
179.35 \\
136.95\end{array}$ & $\begin{array}{l}-7.36 \\
6.62 \\
7.53 \\
-8.24\end{array}$ & $\begin{array}{l}0.93 \\
0.98 \\
0.90 \\
0.32\end{array}$ & & & & & \\
\hline
\end{tabular}


Table S3c.- The ${ }^{17} \mathrm{O}$ NMR parameters for carbamic acid structures. The carbamic acid pairs also show two different carbon environments and hence four different oxygen environments. This is due to them being unsymmetric with respect to the organic linker backbone. In this table $\mathrm{COOH}^{\mathrm{a}}$ refers to the part of the pair with the $\mathrm{C}=\mathrm{O}$ bond pointing towards the backbone. The $\mathrm{COOH}^{\mathrm{b}}$ structure refers to the part of the pair with the $\mathrm{C}-\mathrm{OH}$ pointing towards the backbone.

\begin{tabular}{|c|c|c|c|c|c|c|c|c|c|}
\hline Compound & Site & $\begin{array}{l}\delta_{\text {iso }} \\
(\mathrm{ppm})\end{array}$ & $\begin{array}{l}\mathrm{C}_{\mathrm{Q}} \\
(\mathrm{MHz})\end{array}$ & $\eta_{\mathrm{Q}}$ & Compound & Site & $\begin{array}{l}\delta_{\text {iso }} \\
(\mathrm{ppm})\end{array}$ & $\begin{array}{l}\mathrm{C}_{\mathrm{Q}} \\
(\mathrm{MHz})\end{array}$ & $\eta_{\mathrm{Q}}$ \\
\hline \multirow{4}{*}{$\begin{array}{l}\text { pn- } \\
\mathrm{Mg}_{2} \text { (dobpdc) }\end{array}$} & $\mathrm{COOH}^{\mathrm{a}}$ & 193.07 & -6.99 & 0.95 & \multirow{4}{*}{$\begin{array}{l}\mathrm{mpn}- \\
\mathrm{Mg}_{2} \text { (dobpdc) }\end{array}$} & $\mathrm{COOH}^{\mathrm{a}}$ & 191.84 & -7.04 & 0.92 \\
\hline & $\mathrm{COOH}^{\mathrm{a}}$ & 122.17 & -8.22 & 0.34 & & $\mathrm{COOH}^{\mathrm{a}}$ & 120.16 & -8.22 & 0.34 \\
\hline & $\mathrm{COOH}^{\mathrm{b}}$ & 188.07 & 6.79 & 0.94 & & $\mathrm{COOH}^{\mathrm{b}}$ & 185.29 & 6.78 & 0.94 \\
\hline & $\mathrm{COOH}^{\mathrm{b}}$ & 131.52 & -8.15 & 0.42 & & $\mathrm{COOH}^{\mathrm{b}}$ & 132.22 & -8.11 & 0.39 \\
\hline \multirow{4}{*}{$\begin{array}{l}\mathrm{dmpn}- \\
\mathrm{Mg}_{2} \text { (dobpdc) }\end{array}$} & $\mathrm{COOH}^{\mathrm{a}}$ & 196.48 & -6.94 & 0.97 & \multirow{4}{*}{$\begin{array}{l}\text { dmpn-- } \\
\mathrm{Zn}_{2} \text { (dobpdc) }\end{array}$} & $\mathrm{COOH}^{\mathrm{a}}$ & 194.26 & -6.98 & 0.96 \\
\hline & $\mathrm{COOH}^{\mathrm{a}}$ & 123.71 & -8.31 & 0.39 & & $\mathrm{COOH}^{\mathrm{a}}$ & 124.24 & -8.26 & 0.37 \\
\hline & $\mathrm{COOH}^{\mathrm{b}}$ & 196.61 & 6.78 & 0.92 & & $\mathrm{COOH}^{\mathrm{b}}$ & 194.64 & 6.73 & 0.95 \\
\hline & $\mathrm{COOH}^{\mathrm{b}}$ & 133.41 & -8.11 & 0.40 & & $\mathrm{COOH}^{\mathrm{b}}$ & 134.35 & -8.06 & 0.40 \\
\hline
\end{tabular}





Figure S2. - 2D MQMAS ${ }^{17}$ O NMR (20.0 T, 14 KHz MAS) spectra of selected samples. Only three out of the four expected peaks for chemisorbed $\mathrm{CO}_{2}$ were detected for (dmpn)- $\mathrm{Mg}_{2}$ (dobpdc) and (ii-2)- $\mathrm{Mg}_{2}(\mathrm{dobpdc}$ ) However, it is clear by fitting the $1 \mathrm{D}{ }^{17} \mathrm{O}$ MAS spectra (Figure 3b, Figure 4) that an additional signal at lower chemical shifts is needed to fully deconvolute the lineshape for these materials. Although, a fourth signal is not observed in the MQMAS spectrum, likely owing to the low efficiency of multiple quantum excitation for nuclei with large quadrupolar couplings, this signal can be clearly resolved in the ${ }^{17} \mathrm{O}$ MAS spectrum at $20.0 \mathrm{~T}$ and 23.5 T (Figure 3, SI Figure S3, Figure 4a, SI Figure S7). In all cases, peaks from physisorbed $\mathrm{CO}_{2}$ are not observed in the MQMAS spectra as these species are likely to have negligible quadrupolar couplings. 


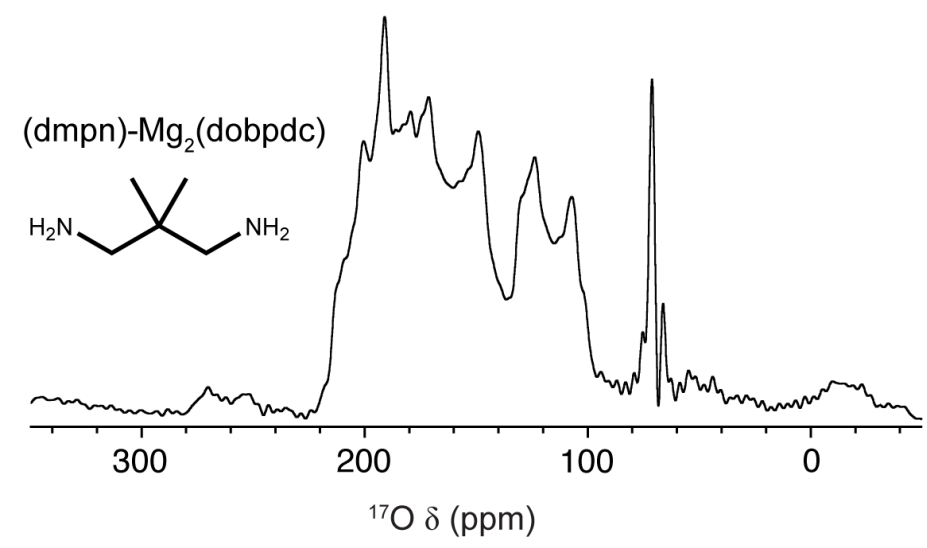

Figure S3. - The ${ }^{17} \mathrm{O}$ NMR spectra of $\mathrm{CO}_{2}$-dosed (dmpn)- $\mathbf{M g}_{2}$ (dobpdc). The spectrum was taken at $23.5 \mathrm{~T}$ with a $20 \mathrm{kHz}$ MAS rate for an independent sample to that shown in the main text at $20.0 \mathrm{~T}$. 


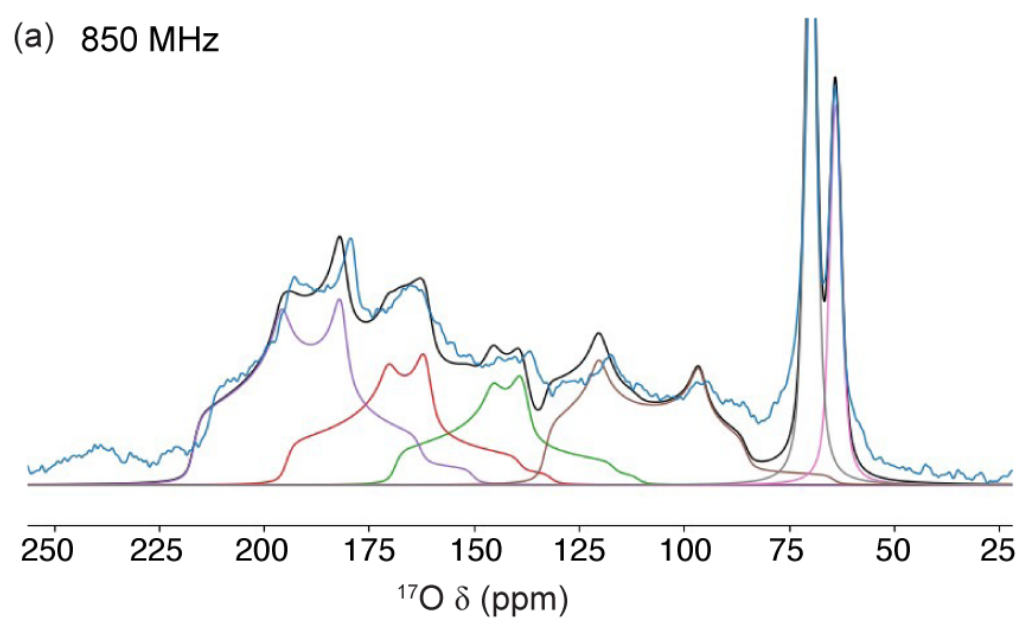

(b) $1 \mathrm{GHz}$

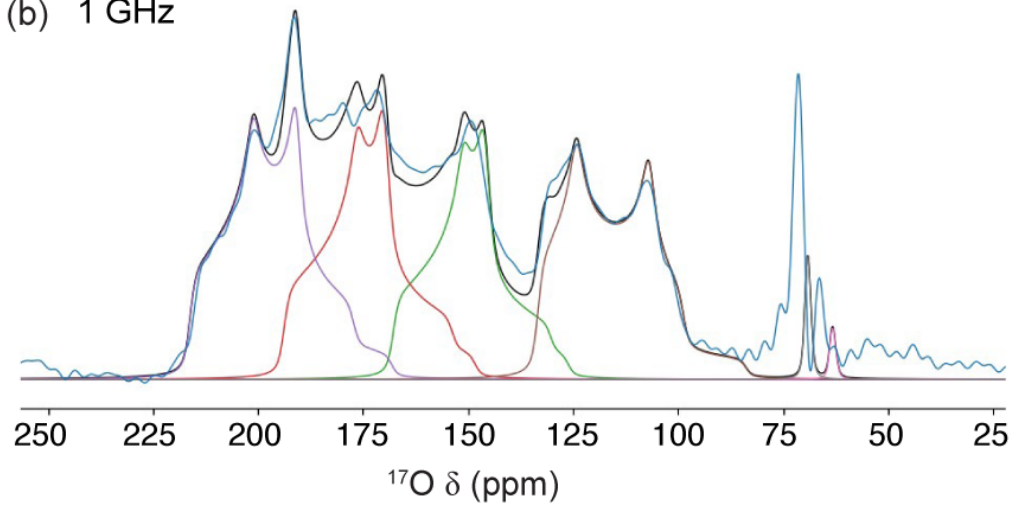

Figure S4. - Simultaneous two field fitting of the ${ }^{17} \mathrm{O}$ NMR spectra of (dmpn)- $\mathrm{Mg}_{2}$ (dobpdc) using the program ssNake. ${ }^{2}$ a) The resulting fit for the ${ }^{17} \mathrm{O}$ NMR data obtained at $850 \mathrm{MHz}(20.0 \mathrm{~T}, 14 \mathrm{kHz}$ MAS). b) The resulting fit for the ${ }^{17} \mathrm{O}$ NMR data obtained at $1 \mathrm{GHz}(23.5 \mathrm{~T}, 20.0 \mathrm{kHz})$. The peaks corresponding to physisorbed $\mathrm{CO}_{2}$ were included in the fit to account for the lower shift intensities in the $850 \mathrm{MHz}$ spectrum. This was done assuming two different environments for physisorbed $\mathrm{CO}_{2}$. This fit did not account for the physisorbed peaks seen in the $1 \mathrm{GHz}$ spectra indicating that other factors beyond field dependence are needed to describe the physisorbed peaks seen. 
(a) (ee-2)-Mg $($ dobpdc)

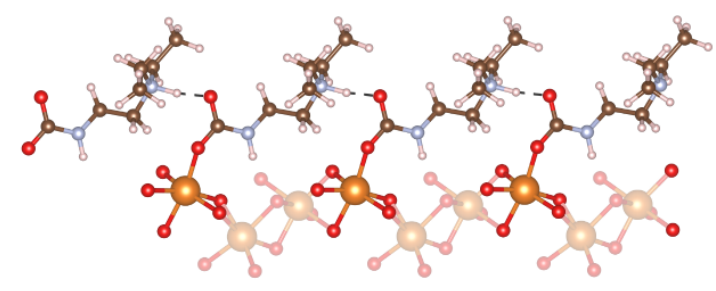

(b) (i-2)-Mg 2 (dobpdc)

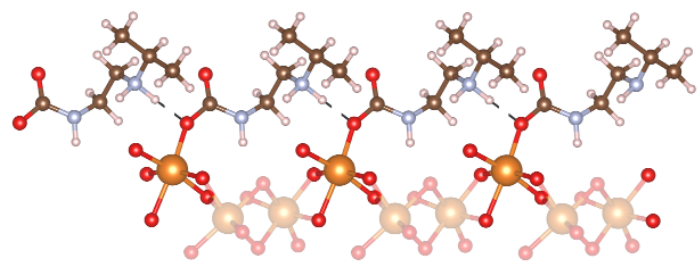

(c) (e-2)-Mg $($ dobpdc)

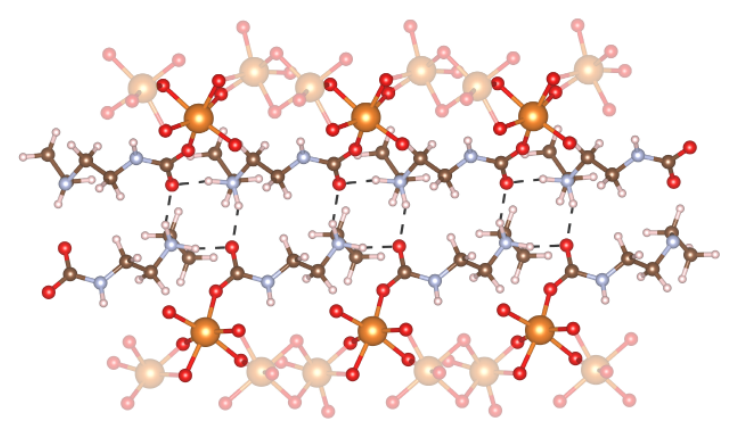

Figure S5. - Schematics of the DFT optimised ammonium carbamate chain structures for $\mathrm{CO}_{2}$-dosed (diamine)$\mathbf{M g}_{2}$ (dobpdc) samples. a) (ee-2) $-\mathrm{Mg}_{2}(\mathrm{dobpdc})-\mathrm{CO}_{2}$ showing H-bonding to the "free" oxygen, b) (i-2)- $\mathrm{Mg}_{2}(\mathrm{dobpdc})-$ $\mathrm{CO}_{2}$ showing $\mathrm{H}$-bonding to the "inserted" oxygen, and c) (e-2)- $\mathrm{Mg}_{2}$ (dobpdc) $-\mathrm{CO}_{2}$ showing $\mathrm{H}$ bonding to the "free"” oxygen and $\mathrm{H}$-bonding between adjacent carbamate chains. 


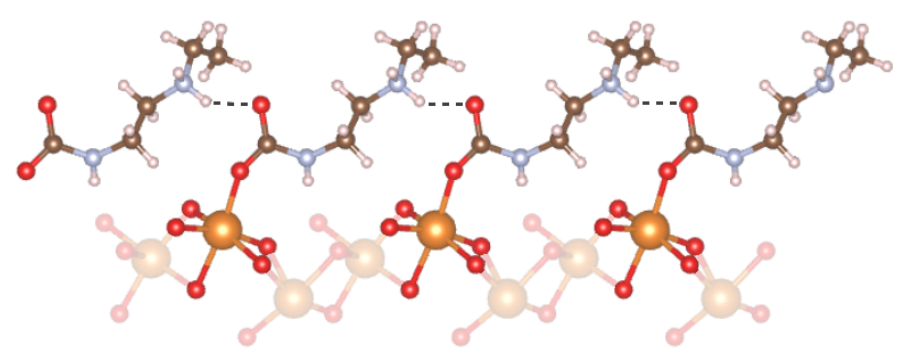

Figure S6. The alternative structure for $\mathrm{CO}_{2}$ dosed (e-2)- $\mathrm{Mg}_{2}(\mathrm{dobpdc})$ in which hydrogen bonding is taking place to the "free" oxygen. Upon geometry optimisation, the hydrogen-bonded proton moved resulting in a structure in which the $\mathrm{CO}_{2}$ was present as carbamic acid.

Table S4. The experimental and DFT calculated NMR parameters for $\mathrm{CO}_{2}$ dosed (e-2)-Mg $\left(\mathrm{Mg}_{2}(\mathrm{doppdc})\right.$. In addition to the DFT structure shown in the main text (Figure 4b, Table 1), two alternative structures were investigated. The carbamic acid structure is the structure resulting from geometry optimisation of the structure Figure S6. The second structure is the same structure as in Figure S6, i.e., without geometry optimisation. This second structure had the same hydrogen bonding arrangement as $\mathrm{CO}_{2}$ dosed (ee-2)- $\mathrm{Mg}_{2}$ (dobpdc) (Figure S5a) and show a better fit between DFT calculated and experimental parameters.

\begin{tabular}{ccccc}
\hline Compound & DFT structure & $\delta{ }^{17} \mathrm{O}(\mathrm{ppm})$ & $\mathrm{C}_{\mathrm{Q}}(\mathrm{MHz})$ & $\eta_{\mathrm{Q}}$ \\
& & Experiment (DFT) & Experiment (DFT) & Experiment (DFT) \\
\hline$(\mathrm{e}-2)-\mathrm{Mg}_{2}$ (dobpdc) & Carbamic acid & M-OCO: 171 (175) & $6.9(7.3)$ & $1.0(1.0)$ \\
$(\mathrm{e}-2)-\mathrm{Mg}_{2}$ (dobpdc) & M-OCO: $197(135)$ & $6.3(7.9)$ & $0.9(0.4)$ \\
& Figure S6 & M-OCO: $171(176)$ & $6.9(6.9)$ & $0.9(0.8)$ \\
& $\begin{array}{c}\text { without geometry } \\
\text { optimisation }\end{array}$ & M-OCO: $197(188)$ & $6.3(7.3)$ & \\
\hline
\end{tabular}




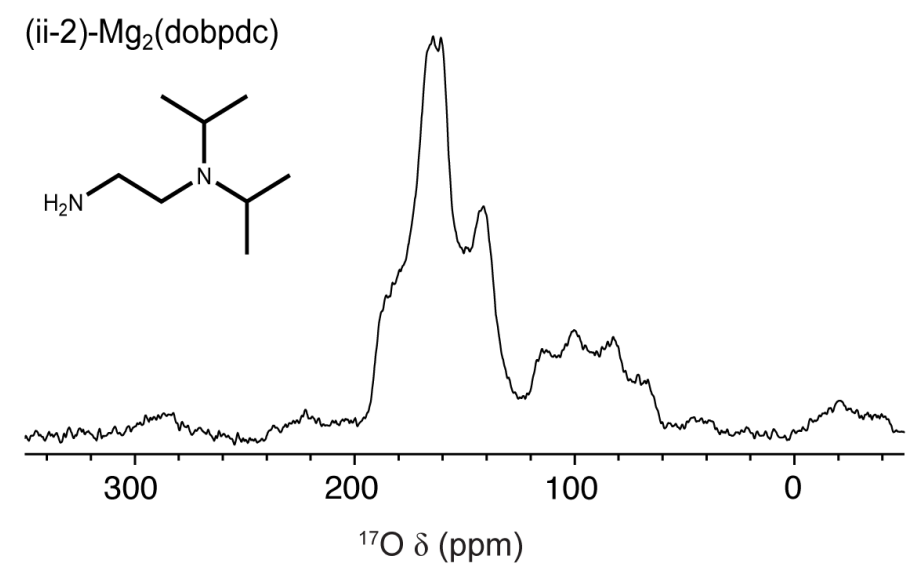

Figure S7. - The ${ }^{17} \mathrm{O}$ NMR spectra of $\mathbf{C O}_{2}$-dosed (ii-2)- $\mathbf{M g}_{2}$ (dobpdc). The spectrum was taken at $20.0 \mathrm{~T}$ with a $14 \mathrm{kHz}$ MAS rate for an independent sample to that shown in the main text at $23.5 \mathrm{~T}$. 
(a) $850 \mathrm{MHz}$

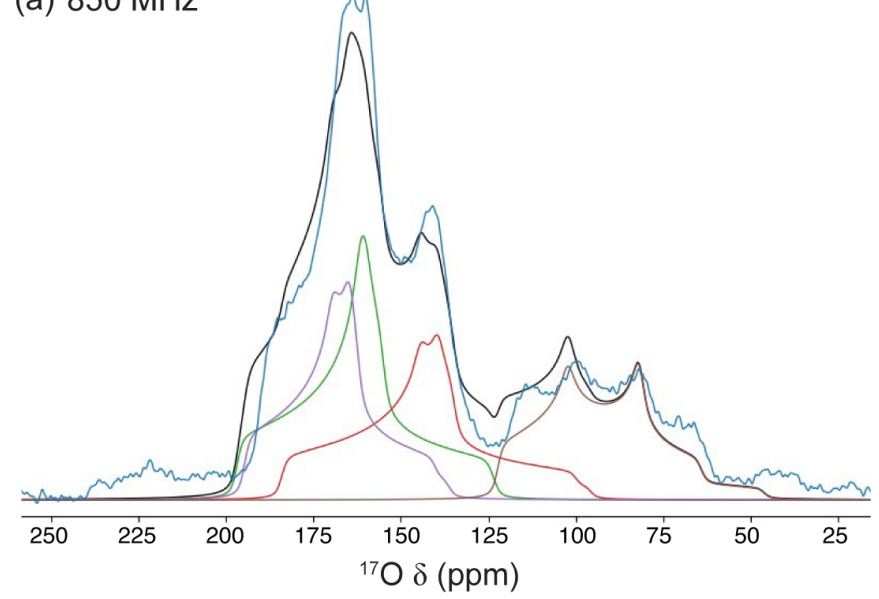

(b) $1 \mathrm{GHz}$

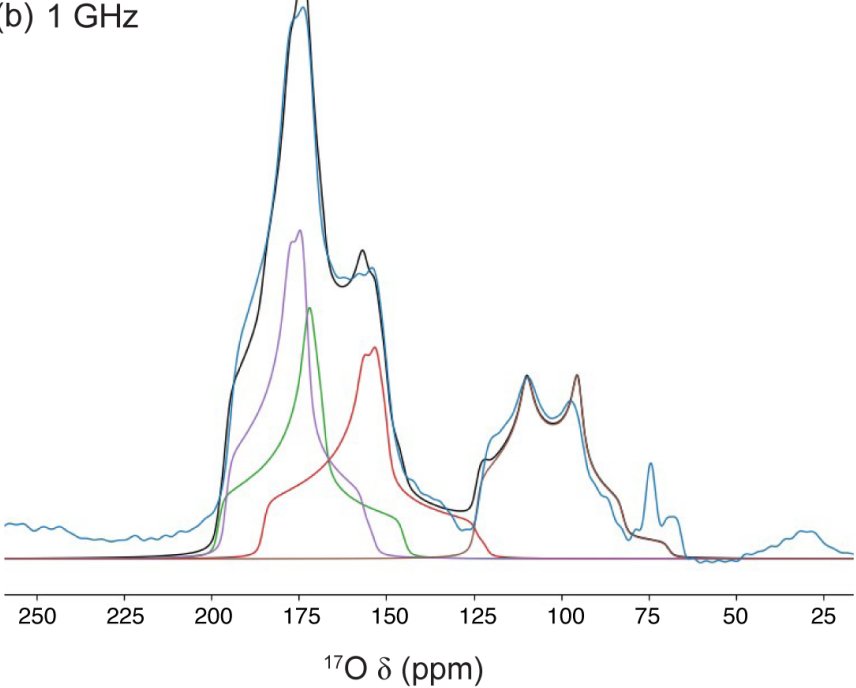

Figure S8. - Simultaneous two field fitting of the ${ }^{17} \mathrm{O}$ NMR spectra of (ii-2)- $\mathrm{Mg}_{2}(\mathrm{dobpdc})$ using the program ssNake. ${ }^{2}$ a) The resulting fit for the ${ }^{17} \mathrm{O}$ NMR data obtained at $850 \mathrm{MHz}(20.0 \mathrm{~T}, 14 \mathrm{kHz}$ MAS). b) The resulting fit for the ${ }^{17} \mathrm{O}$ NMR data obtained at $1 \mathrm{GHz}(23.5 \mathrm{~T}, 20.0 \mathrm{kHz})$. 

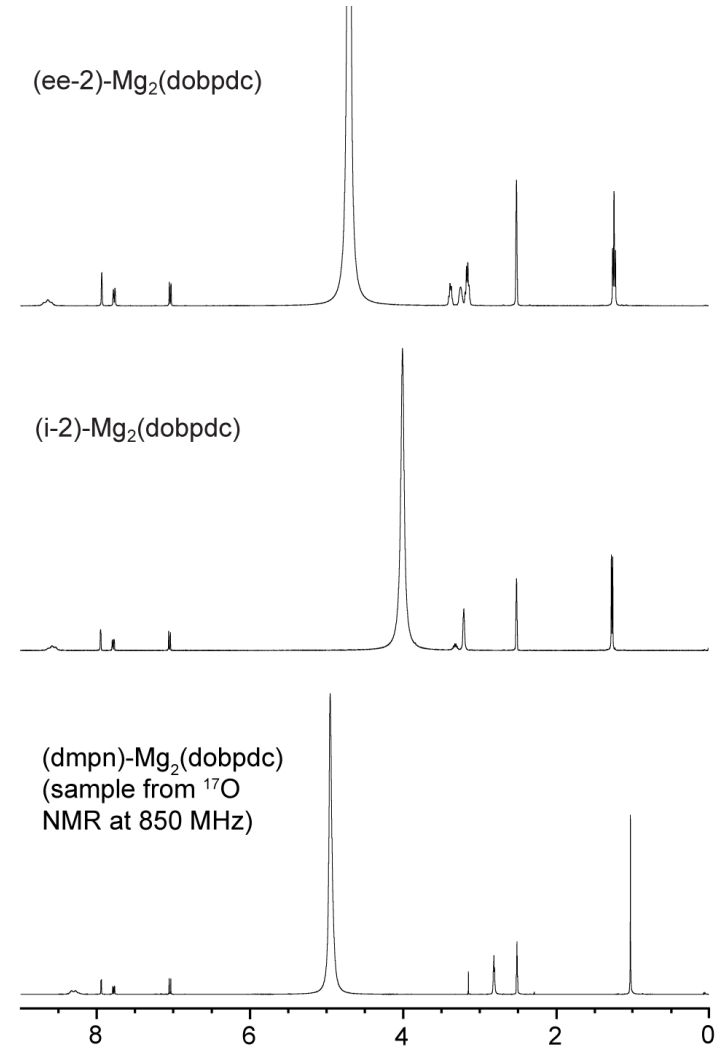

${ }^{1} \mathrm{H} \delta(\mathrm{ppm})$
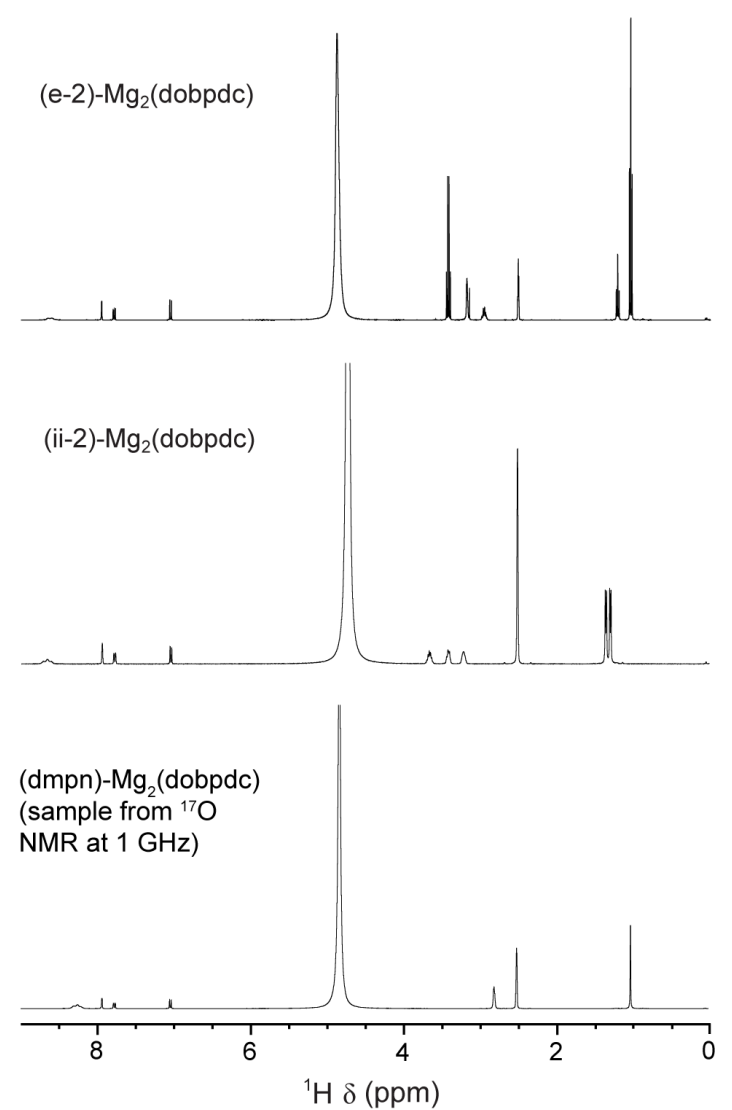

Figure S9. - Quantitative solution ${ }^{1} \mathrm{H}$ NMR (400 MHz) spectra of acid-digested (diamine)-Mg 2 (dobpdc) samples. 
Table S5. - Stoichiometries and diamine loadings of amine-functionalised frameworks determined by ${ }^{1} \mathrm{H}$ solution-state NMR of acid-digested samples.

\begin{tabular}{|l|l|l|}
\hline Diamine & Formula & Diamine loading \\
\hline i-2 & $\mathrm{Mg}_{2}($ dobpdc $)(\mathrm{i}-2)_{1.92}$ & $96 \%$ \\
\hline e-2 & $\mathrm{Mg}_{2}($ dobpdc $)(\mathrm{e}-2)_{2.09}$ & $104 \%$ \\
\hline ee-2 & $\mathrm{Mg}_{2}($ dobpdc $)(\mathrm{ee}-2)_{1.89}$ & $95 \%$ \\
\hline dmpn -20.0 T sample & $\mathrm{Mg}_{2}($ dobpdc $)(\mathrm{dmpn})_{2.02}$ & $101 \%$ \\
\hline dmpn -23.5 T sample & $\mathrm{Mg}_{2}($ dobpdc $)(\mathrm{dmpn})_{2.00}$ & $100 \%$ \\
\hline ii-2-20.0 T sample & $\mathrm{Mg}_{2}($ dobpdc $)(\mathrm{ii}-2)_{1.88}$ & $94 \%$ \\
\hline ii-2 - 23.5 T sample & $\mathrm{Mg}_{2}($ dobpdc $)(\mathrm{ii}-2)_{2.04}$ & $102 \%$ \\
\hline
\end{tabular}



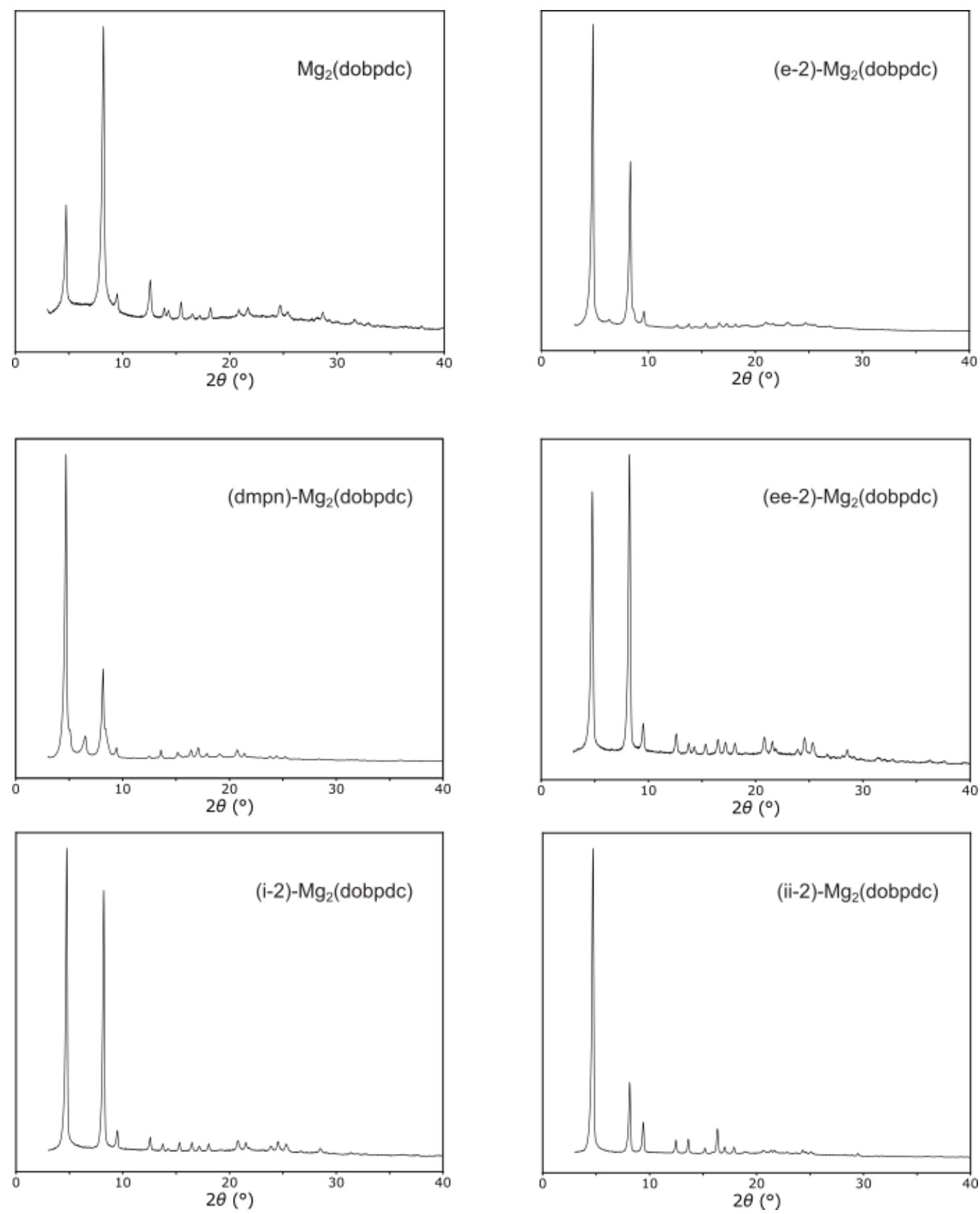

Figure S10. - PXRD patterns of $\mathrm{Mg}_{2}\left(\right.$ dobpdc) and the investigated (diamine)- $\mathrm{Mg}_{2}(\mathrm{dobpdc})$ samples. The PXRD was taken using a Malvern Panalytical Empyrean instrument equipped with an X'celerator Scientific detector, using non-monochromated $\mathrm{Cu} \mathrm{K} \alpha$ radiation $(\lambda=1.5418 \AA$ ). Each sample was placed in a glass sample holder and measured in reflection geometry with sample spinning. The data was collected at room temperature over a $2 \theta$ range of $2-40^{\circ}$, with an effective step size of $0.01-0.02^{\circ}$ and a total collection time of $45 \mathrm{~min}$. 


\section{Extended data References}

(1) Kim, E. J.; Siegelman, R. L.; Jiang, H. Z. H.; Forse, A. C.; Lee, J. H.; Martell, J. D.; Milner, P. J.; Falkowski, J. M.; Neaton, J. B.; Reimer, J. A.; Weston, S. C.; Long, J. R. Cooperative Carbon Capture and Steam Regeneration with Tetraamine-Appended Metal-Organic Frameworks. Science 2020, 369 (6502). https://doi.org/10.1126/science.abb3976.

(2) van Meerten, S. G. J.; Franssen, W. M. J.; Kentgens, A. P. M. SsNake: A Cross-Platform Open-Source NMR Data Processing and Fitting Application. Journal of Magnetic Resonance 2019, 301, 56-66. https://doi.org/10.1016/J.JMR.2019.02.006.

(3) Martell, J. D.; Porter-Zasada, L. B.; Forse, A. C.; Siegelman, R. L.; Gonzalez, M. I.; Oktawiec, J.; Runčevski, T.; Xu, J.; Srebro-Hooper, M.; Milner, P. J.; Colwell, K. A.; Autschbach, J.; Reimer, J. A.; Long, J. R.

Enantioselective Recognition of Ammonium Carbamates in a Chiral Metal-Organic Framework. Journal of the American Chemical Society 2017, 139 (44). https://doi.org/10.1021/jacs.7b09983.

(4) Čendak, T.; Sequeira, L.; Sardo, M.; Valente, A.; Pinto, M. L.; Mafra, L. Detecting Proton Transfer in CO2 Species Chemisorbed on Amine-Modified Mesoporous Silicas by Using 13C NMR Chemical Shift Anisotropy and Smart Control of Amine Surface Density. Chemistry - A European Journal 2018, 24 (40).

https://doi.org/10.1002/chem.201800930. 